\title{
TU/e EmonOWEN

\section{Measurement and prediction of solid sphere trajectories in accelerated gas flow}

Citation for published version (APA):

Geld, van der, C. W. M. (1997). Measurement and prediction of solid sphere trajectories in accelerated gas flow. International Journal of Multiphase Flow, 23(2), 357-376. https://doi.org/10.1016/S0301-9322(96)00069-9

DOI:

10.1016/S0301-9322(96)00069-9

Document status and date:

Published: 01/01/1997

\section{Document Version:}

Publisher's PDF, also known as Version of Record (includes final page, issue and volume numbers)

\section{Please check the document version of this publication:}

- A submitted manuscript is the version of the article upon submission and before peer-review. There can be important differences between the submitted version and the official published version of record. People interested in the research are advised to contact the author for the final version of the publication, or visit the $\mathrm{DOI}$ to the publisher's website.

- The final author version and the galley proof are versions of the publication after peer review.

- The final published version features the final layout of the paper including the volume, issue and page numbers.

Link to publication

\section{General rights}

Copyright and moral rights for the publications made accessible in the public portal are retained by the authors and/or other copyright owners and it is a condition of accessing publications that users recognise and abide by the legal requirements associated with these rights.

- Users may download and print one copy of any publication from the public portal for the purpose of private study or research.

- You may not further distribute the material or use it for any profit-making activity or commercial gain

- You may freely distribute the URL identifying the publication in the public portal.

If the publication is distributed under the terms of Article 25fa of the Dutch Copyright Act, indicated by the "Taverne" license above, please follow below link for the End User Agreement:

www.tue.nl/taverne

Take down policy

If you believe that this document breaches copyright please contact us at:

openaccess@tue.nl

providing details and we will investigate your claim. 


\title{
MEASUREMENT AND PREDICTION OF SOLID SPHERE TRAJECTORIES IN ACCELERATED GAS FLOW
}

\author{
C. W. M. VAN DER GELD \\ Faculty of Mechanical Engineering, Eindhoven University of Technology, P.O. Box 513, 5600 MB \\ Eindhoven, The Netherlands
}

(Received 2 June 1996; in revised form 19 September 1996)

\begin{abstract}
Trajectories are measured and compared with computed trajectories of solid particles with a diameter of $1-2 \mathrm{~mm}$ in downward gas flow near a solid cylinder with a diameter, $d_{c}$, of $25 \mathrm{~mm}$. The Reynolds number based on $d_{\mathrm{c}}$ has been varied from 3000-13,000. The particle Reynolds numbers, based on the relative velocity $\left|\mathbf{u}_{\mathrm{G}}-\mathbf{u}_{\mathrm{p}}\right|$, ranged from 0 to 2000 . Of all forces other than gravity, drag is dominant, although the pressure gradient and added mass forces for $\operatorname{Re}_{\mathrm{c}}>10,000$ have the same order of magnitude. The Basset force can be neglected. The correlation [3], originally derived by Sridhar and Katz (1995) for the lift force coefficient of bubbles, has been found to be appropriate for freely moving solid particles with shear number less than 0.04. 1997 Elsevier Science Ltd. All rights reserved.
\end{abstract}

Key Words: particle, trajectory, two-phase, lift force, added mass force

\section{INTRODUCTION}

Dispersed two-phase flows passing obstacles have a manifold occurrence in industrial applications, including the petroleum, food, power and process industries, e.g. in cat-cracking units, engines for land transport, gas turbine engines. A strong interaction between the carrier fluid that possesses a non-uniform velocity field and the dispersed phase usually leads to highly non-uniform distributions that affect heat transfer and pressure drop. In the fine atomization of fuel that occurs in conventional gas-carburettor based mixing systems, for example, the gas at 30-40 m/s strongly interacts with small bodies that initially move at about $70 \mathrm{~m} / \mathrm{s}$ (Knubben 1995). The computation of particle trajectories is important to enable the prediction of phase distributions. Single particle trajectories are usually computed in a Lagrangian approach with the aid of a momentum balance (Meng and van der Geld 1994). Several contributions to this balance can be distinguished. They are discussed in the following.

Usually the drag force is dominant. The quasi-steady drag, in unsteady flows, is automatically accounted for if the steady drag coefficient is used together with the instantaneous relative velocity on which the particle Reynolds number is based (Mei and Klausner 1992; Odar and Hamilton 1964). The standard drag coefficient is well established (Clift et al. 1978). Inviscid effects are comparable to drag forces if large bluff bodies are accelerated. An example is the unsteady motion of large airships in non-uniform flows, another is marine structures in currents. Inviscid theory yields lift, added mass and pressure gradient forces that for smaller bodies were merely applied to bubbles at high enough Reynolds number (Hunt et al. 1994; Sridhar and Katz 1995). These forces are, however, in common practice also important for particles with a density higher than the surrounding gas or fluid if relative velocity and acceleration are large (Magnaudet et al. 1995). Such a situation occurs in the creation of sprays in some nozzles and in two-phase flows through a sudden expansion or venturi. In this paper, particle trajectories are studied of spherical solid particles that have a diameter of 1-2 $\mathrm{mm}$ and are injected at large relative velocity in air that is accelerated in the vicinity of a solid cylinder. Typical particle Reynolds numbers, based on the relative velocity and the particle diameter, $d_{\mathrm{p}}$, are in the range $300-1700$ with excursions to 0 and 2000. The pressure gradient and added mass forces will be shown to have significant contributions because of the large (relative) accelerations. The size and weight of the particles has been chosen relatively large to exclude the effect of turbulence as much as possible. 
Some forces on the particles, such as the Basset (or rather: Boussinesq) history force, are often neglected without a proper justification. In the present study all known forces on particles are accounted for. The history force accounts for the unsteady (viscous) diffusion of vorticity around the sphere. Since the particles of this study are rigid, the zero-slip condition has to be satisfied. This simplifies the more complicated history integral as derived by Michaelides and Feng (1995) to the well-known Basset one. The turbulence induced particle accelerations are probably negligible in the Basset term even for small particles (Ahmadi and Goldschmidt 1971). The accelerations that occur in the Basset integral can not be derived from frame indifference, as shown by Magnaudet et al. (1995), because of inertia effects (i.e. non-zero relative Reynolds numbers) involved. The appropriate form of the accelerations as given by Magnaudet et al. (1995) has been used in this paper. The expression used for the history force, the usual Basset integral, may not be appropriate for the prevailing conditions, still, because of the assumptions on which its derivation was based (Maxey and Riley 1983; Mei and Klausner 1992). For Reynolds numbers increasing above unity, for example, the Basset-Boussinesq force decreases (Mei et al. 1991; Mei and Adrian 1992). It will be examined whether an expression like the Basset integral, taken to be an upper limit, has a significant contribution or not without trying to assess the validity of the expression involved. This is the usual approach, see e.g. Liang and Michaelides (1992).

A general expression for the lift force on a sphere in a rotational straining flow does not exist, even if viscous effects at the sphere surface are neglected. Neglecting these effects, Auton et al. (1988) in a lucid article showed that in the limit of a weak, slowly varying shear flow the following expression for the lift force, $\mathbf{F}_{L}$, is valid:

$$
\mathbf{F}_{\mathrm{L}}=C_{\mathrm{L}} \cdot \rho_{\mathrm{G}} \cdot \forall_{\mathrm{p}} \cdot\left(\mathbf{u}_{\mathrm{G}}-\mathbf{u}_{\mathrm{p}}\right) \times \omega .
$$

Here $\mathbf{u}_{\mathrm{p}}$ is the particle velocity, suffice $\mathrm{G}$ refers to the gas, $\rho$ is the mass density, $\forall_{\mathrm{p}}$ is the volume of the particle, $\omega$ is the vorticity $\boldsymbol{\nabla} \times \mathbf{u}_{\mathrm{G}}$, and $C_{\mathrm{L}}$ is discussed below. Only first order effects in the stress tensor and the vorticity were considered in the derivation of [1], that can be added to the forces associated with the acceleration of the flow. $C_{\mathrm{L}}$ is the conventional lift coefficient which is related to the purely rotational lift coefficient, $C_{\mathrm{L} \Omega}$, that accounts for vorticity distortion by

$$
C_{\mathrm{L}}=0.5\left(1+C_{\mathrm{AM}}\right)+C_{\mathrm{L} \Omega} .
$$

Here $C_{\mathrm{AM}}$ is the added mass coefficient, 0.5 for a sphere. Auton (1987) showed that $C_{\mathrm{L}}=0.5$ in weak shear flow (implying a negative value of $C_{1 \Omega}$ ). For bubbles at finite Reynolds number, the added-mass coefficient was found to be the same as in creeping flow and in potential flow (Mei and Klausner 1992). For particles, also the lift was found to be independent of the Reynolds number, while $C_{\mathrm{AM}}$ was found to be independent of the acceleration number (Chang 1992).

An expression for the lift force on a freely moving solid particle in the asymptotic limit of low particle Reynolds number, $\mathrm{Re}_{\mathrm{p}}$, was derived by Saffman, see Leal (1980). It acts in the same direction as $\mathbf{F}_{\mathrm{L}}$ of [1] and is also caused by the vorticity in the flow. $\dagger$ Mei and Klausner (1992) derived an interpolation formula based on the expression of Saffman and numerical results for finite particle Reynolds numbers and zero rotation obtained by others. Recently, Mollinger (1995) measured the fluctuating lift force on a solid sphere in a viscous sublayer and Miyazaki et al. (1995) computed lift and drag on a sphere in slow shear flow for the time-dependent case. For particle Reynolds numbers less than 160, a lift was computed in the absence of fluid shear by Kim et al. (1993), if a second, similar particle is present. The solid sphere was not allowed to rotate in these predictions. The particle wake structure was observed to be rather complex and the lift force repelling if the other particle has a distance of the order of several particle diameters. At $\operatorname{Re}_{\mathrm{p}}>300$, the vortex shedding past a sphere is non-axisymmetrical even in the absence of another particle (Kim and Pearlstein 1990). The vortices shed probably interact with vortices detached from another body nearby, e.g. a solid cylinder as present in this study. At large Reynolds numbers, the wake structure of a spherical particle in flow near a larger body is therefore expected to be

tThis is not fully transparent in the expressions usually employed for the Saffman force. However, the homogeneity of the shear $\mathbf{n} \cdot \nabla\left(\mathbf{t} \cdot \mathbf{u}_{G}\right)$ was an essential ingredient in the derivation of Saffman; $\mathbf{n}$ and $\mathbf{t}$ are the normal and the tangent to the direction of motion of the particle. 

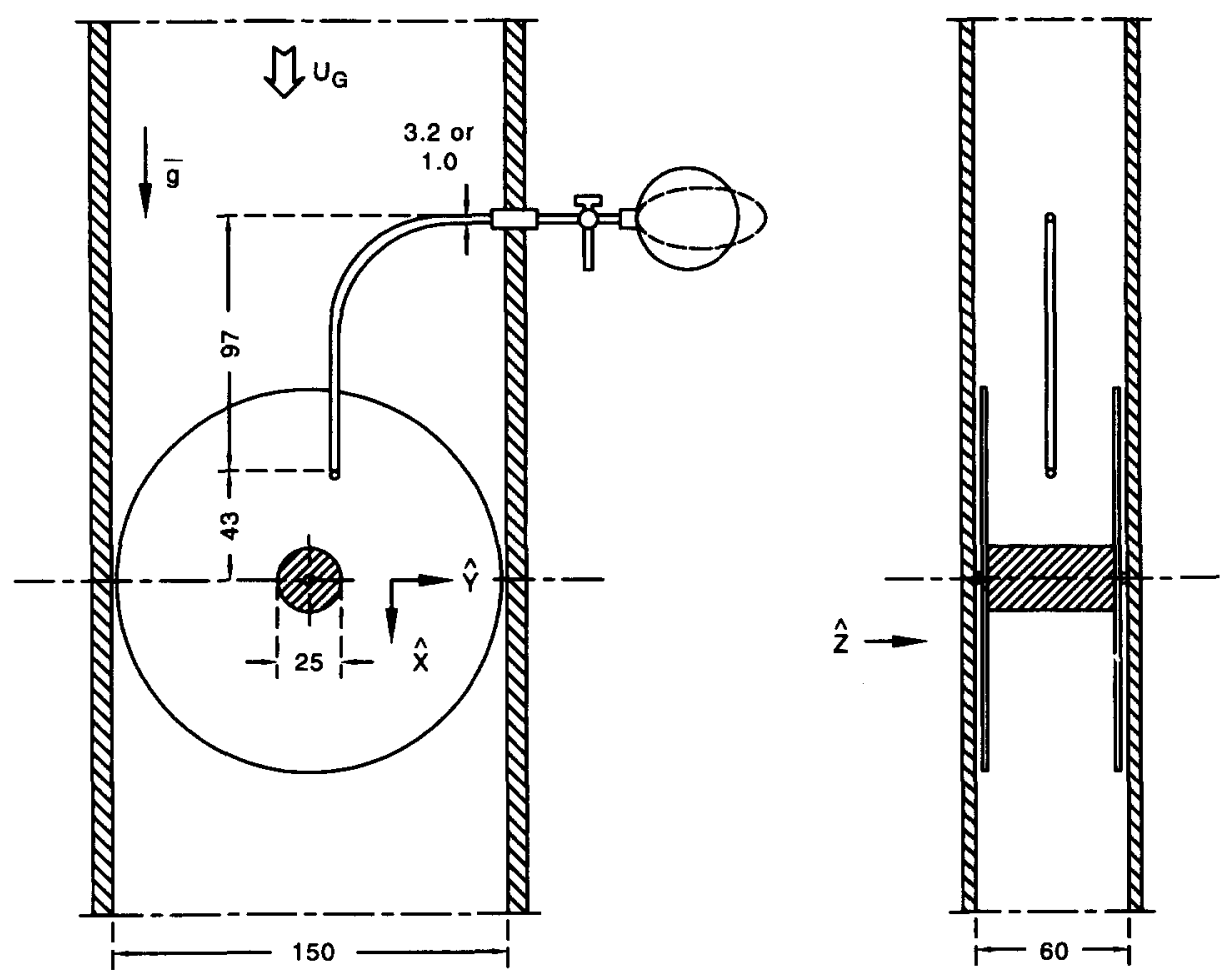

Figure 1. Schematic of test section and injection system.

that complex that repelling lift forces may occur even in the absence of vorticity in the approaching flow.

Because of an asymmetric wake, a rotating sphere experiences a significant lift even in the absence of fluid shear and the absence of other particles, if the particle Reynolds number is high $(> \pm 2000)$. This is often named the Magnus effect. If the surface velocity is less than 0.6 times the relative velocity this lift force for Reynolds numbers close to the critical transition might even act in the direction opposite to that of other cases (Clift et al. 1978). The particles in the visualisation studies presented in this paper are injected without spin, and the unforced spin velocity taken up in the proximity of the cylinder is small. Barkla and Auchterlone (1971) measured lift coefficients of spinning, solid spheres in quiescent fluids at Reynolds numbers between 1500 and 3000 . Values of $C_{\mathrm{L}}$ ranged from 0.04 to 0.1 , independent of $\mathrm{Re}_{\mathrm{p}}$ but depending on the shear number, $\alpha$ :

$$
\alpha \stackrel{\text { def }}{=} \frac{1}{2} \omega \cdot d_{\mathrm{p}} /\left|\mathbf{u}_{\mathrm{G}}-\mathbf{u}_{\mathrm{p}}\right|
$$

that ranged from 3 to 10 . Sridhar and Katz (1995) measured the lift of bubbles entrained by a vortex at Reynolds numbers between 20 and 80 . The presence of trace impurities caused their bubbles, with diameters of ca. $0.6 \mathrm{~mm}$, to behave like solid spheres. This is manifested by, e.g. the solid drag force coefficient which was measured by them to hold for these bubbles. Values of $C_{L}$ ranged from 1.2 to 23 , were independent of $\operatorname{Re}_{\mathrm{p}}$ and were correlated $\dagger$ by

$$
C_{\mathrm{L}}=0.22 \cdot \alpha^{-0.75}
$$

for $\alpha$ in the range $0.002-0.1$. Extrapolating this correlation to $\alpha=10$ about the same $C_{\mathrm{L}}$-values as measured by Barkla and Auchterlone (1971) are found.

In the present study the expression [1] will be applied to rigid spheres that move at high particle Reynolds number through flows with finite, non-uniform vorticity generated near a solid cylinder. The shear number is less than 0.06 . This is an order of magnitude below that of other measurements on solid spheres in the literature, but in the range of the bubble measurements of Sridhar and Katz

$\dagger$ For ease of reference, Sridhar and Katz (1995) defined the lift coefficient as $8 F_{\mathrm{L}} /\left(\pi \rho_{\mathrm{j}} \cdot d_{\mathrm{F}}^{2} \cdot\left|u_{\mathrm{i}}-u_{\mathrm{p}}\right|^{3}\right)$, which is equivalent to $8 C_{\mathrm{L}} \cdot x / 3$. 


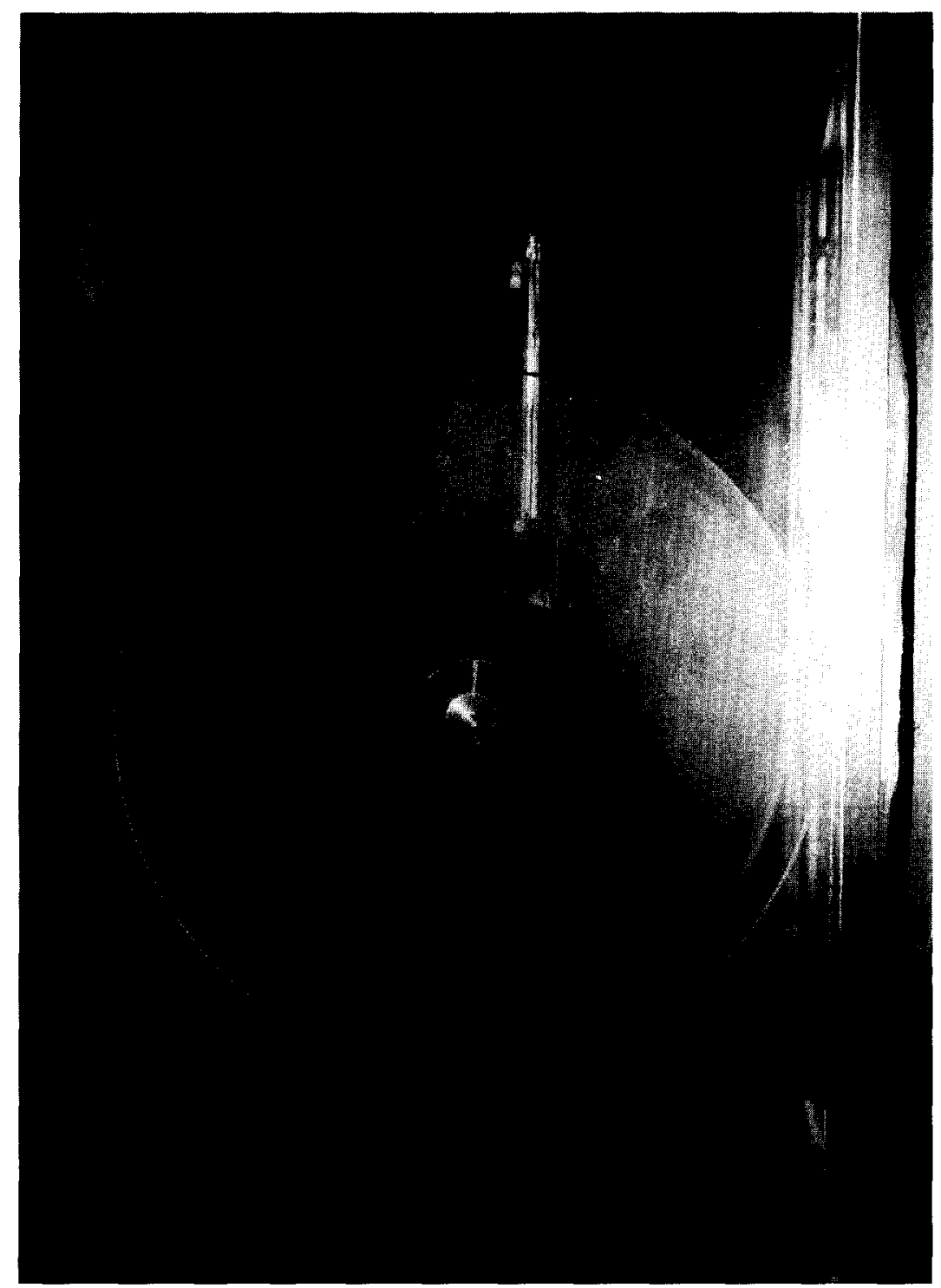

Figure 2. Photograph of the test rig.

(1995), see above. The present measurements may help to assess the dependence of $C_{\mathrm{L}}$ on $\alpha$ for rigid spheres. $C_{\mathrm{L}}$ is considered as a lumped parameter that accommodates for all physical effects that may cause lift. By comparison of visualisations with computations of particle trajectories, the value of $C_{\mathrm{L}}$ will be determined. For this, the value of the drag coefficient has to be assessed first. The unsteady gas flow around the cylinder is modeled with a finite element method in which the particle motion is assumed not to affect the undisturbed gas flow.

Table 1. Solid sphere drag coefficient correlations used. $\mathrm{Re}_{\mathrm{p}}$ is the particle Reynolds number $d_{\mathrm{p}} \cdot\left|u_{\mathrm{G}}-u_{\mathrm{p}}\right| / v_{\mathrm{G}}$ and $w^{\prime} \stackrel{\text { def }}{=} \log _{10}\left(\operatorname{Re}_{\mathrm{p}}\right)$. Source: Clift et al. (1978)

\begin{tabular}{ll}
\hline $\mathrm{Re}_{\mathrm{p}}$ range & \multicolumn{1}{c}{$C_{\mathrm{D}}$ correlation } \\
\hline $0.01-20$ & $C_{\mathrm{D}}=24 / \operatorname{Re}_{\mathrm{p}} \cdot\left(1+0.1315 \cdot \mathrm{Re}_{\mathrm{p}}^{0.82-0.15 \cdot w}\right)$ \\
$20-260$ & $C_{\mathrm{D}}=24 / \operatorname{Re}_{\mathrm{p}} \cdot\left(1+0.1935 \cdot \mathrm{Re}_{\mathrm{p}}^{0.605}\right)$ \\
$260-1500$ & $\log _{10}\left(C_{\mathrm{D}}\right)=1.6435-1.1242 \cdot w+0.1558 \cdot w^{2}$ \\
$1500-120,000$ & $\log _{10}\left(C_{\mathrm{D}}\right)=-2.4571+2.5558 \cdot w-0.9295 \cdot w^{2}+0.1049 \cdot w^{3}$ \\
\hline
\end{tabular}




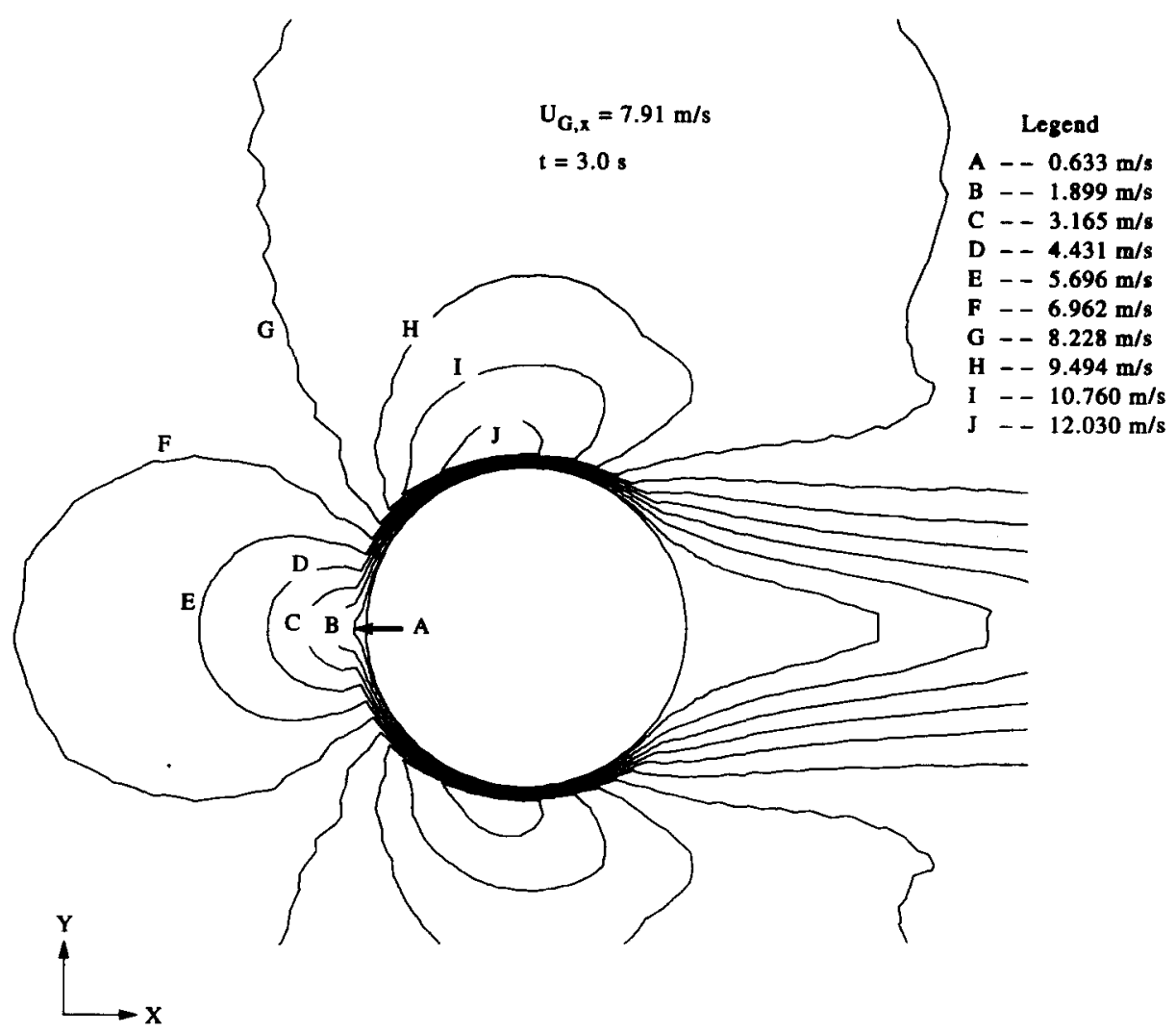

Figure 3. Computed isovelocity contours; values in $\mathrm{m} / \mathrm{s} ; u_{\mathrm{G} x}=7.91 \mathrm{~m} / \mathrm{s}$.

\section{EXPERIMENTAL}

To visualize particle trajectories in a vertical downflow of air near a cylinder, a test rig has been built comprising of a $2.2 \mathrm{~kW}$ blower, tubing, flow straighteners and a $60 \times 150 \mathrm{~mm}^{2}$ rectangular perspex test section with a height of $100 \mathrm{~cm}$, see figure 1 . A flow straightener, designed according to VDI (1991, Blatt 1) is positioned $150 \mathrm{~cm}$ upstream of the test section to reduce secondary flow due to a bend. The blockage ratio, defined as the percentage of the cross section occupied by the cylinder, is $14 \%$ for a cylinder diameter of $25 \mathrm{~mm}$ which according to Cantwell and Coles (1983) suffices to reduce effects of wall confinement. Endplates are applied to isolate the flow over the cylinder from the boundary layers on the walls of the test section and to create a two-dimensional mean flow (Kourta et al. 1987), see figure 2.

Particles are injected ca. $45 \mathrm{~mm}$ upstream of the centre of the cylinder in the direction of the flow. The injection system is a manually operated system, which introduces separate, spherical, polystyrene particles in the air flow, see figure 1. Air is sucked out of or blown into a glass or steel capillary with an outer diameter of 3.2 or $1.0 \mathrm{~mm}$. The underpressure inside keeps the particle from falling until a small valve is gradually opened. To minimize the influence of this capillary on the gas flow, it is bent straight vertically over a length of $97 \mathrm{~mm}$, see figure 1 . The initial velocity of the particle at injection is about $0.5 \mathrm{~m} / \mathrm{s}$.

Velocity profiles have been measured with the aid of a Dantec ${ }^{\mathrm{tm}}$ laser-Doppler anemometer, fitted with a two-channel fiber probe with a $200 \mathrm{~mm}$ lense, operated in backscatter mode and powered by a $3 \mathrm{~W}$ argon laser and mounted on a 3 -D traversing table. Two velocity components are measured simultaneously. The measuring volume is $1.1 \times 0.5 \times 0.5 \mathrm{~mm}^{3}(z \times x \times y$, see figure 1$)$. A counterprocessor with a data rate up to $155 \mathrm{kHz}$ has been used to analyze the signals provided by oil drop tracers with a diameter of about $2 \mu \mathrm{m}$.

Velocity profiles upstream and in the vicinity of the cylinder have been measured for gas velocities ranging from 2.0 to $7.91 \mathrm{~m} / \mathrm{s}$. The measurements have been repeated once. At seven heights above and next to the cylinder axis $x$-and $y$-components of the velocity $\mathbf{u}_{\mathrm{G}}$ of the gas have 
been measured as a function of the $y$-coodinate. The dependency of these components on the $z$-coordinate has been measured upstream of the cylinder at one location only since all particles have been injected in the centre plane, see figure 1 . The velocity profile has been found to be flat over a distance of $60 \mathrm{~mm}$ in $y$-direction and over a distance of $15 \mathrm{~mm}$ in $z$-direction, making the problem essentially two-dimensional with uniform approach velocity.

The air flow rate has been measured with a calibrated orifice with the required (VDI, 1991, DIN 1952, p. Lc3) upstream $\left(20 \times d_{\text {tube }}\right)$ and downstream $\left(6 \times d_{\text {tube }}\right)$ straight pipe lengths amply available. The calibration has been checked on a regular basis with the aid of an Airfow TA5 thermal anemometer. The gas velocities 2.0, 4.0, 6.0 and 7.91 (maximum possible) have been used in the visualisation studies.

Photographs have been made with 3200 ASA films and a Nikon F70 camera mounted at a fixed distance from the test section. A stroboscope illuminated the observation area at $400 \mathrm{~Hz}$.

The measuring strategy has been as follows. First, a grid was placed in the plane where the particles are injected. The camera was focused at a point of the cylinder in this plane. Optical distortion caused the photographed grid to be non-uniform, which has been taken into account in the following way. Slides of the grid system have been projected on a large screen and the distances indicated by the grid have been measured from the screen. A transformation formula (based on second order polynomials) has been deduced from these measurements. Projected slides of particle motion have, subsequently, been analyzed in the following way. At each of these slides the same particle is observed at different locations. These locations have been measured from the screen and transformed to actual distances to the cylinder with the aid of the transformation formula. Also the particle diameter has been measured from the photographed contours on the screen.

The accuracy of the location measurement is $0.3 \mathrm{~mm}$ of the projection screen corresponding to $0.04 \mathrm{~mm}$ in real distances.

Additionally, 10 trajectories have been measured with a high-speed motion camera at 1000 frames per second. A 'cold light' lamp was in this case focused on the observation volume of the test section. A transparent grid was filmed prior to the actual particle measurements to allow for

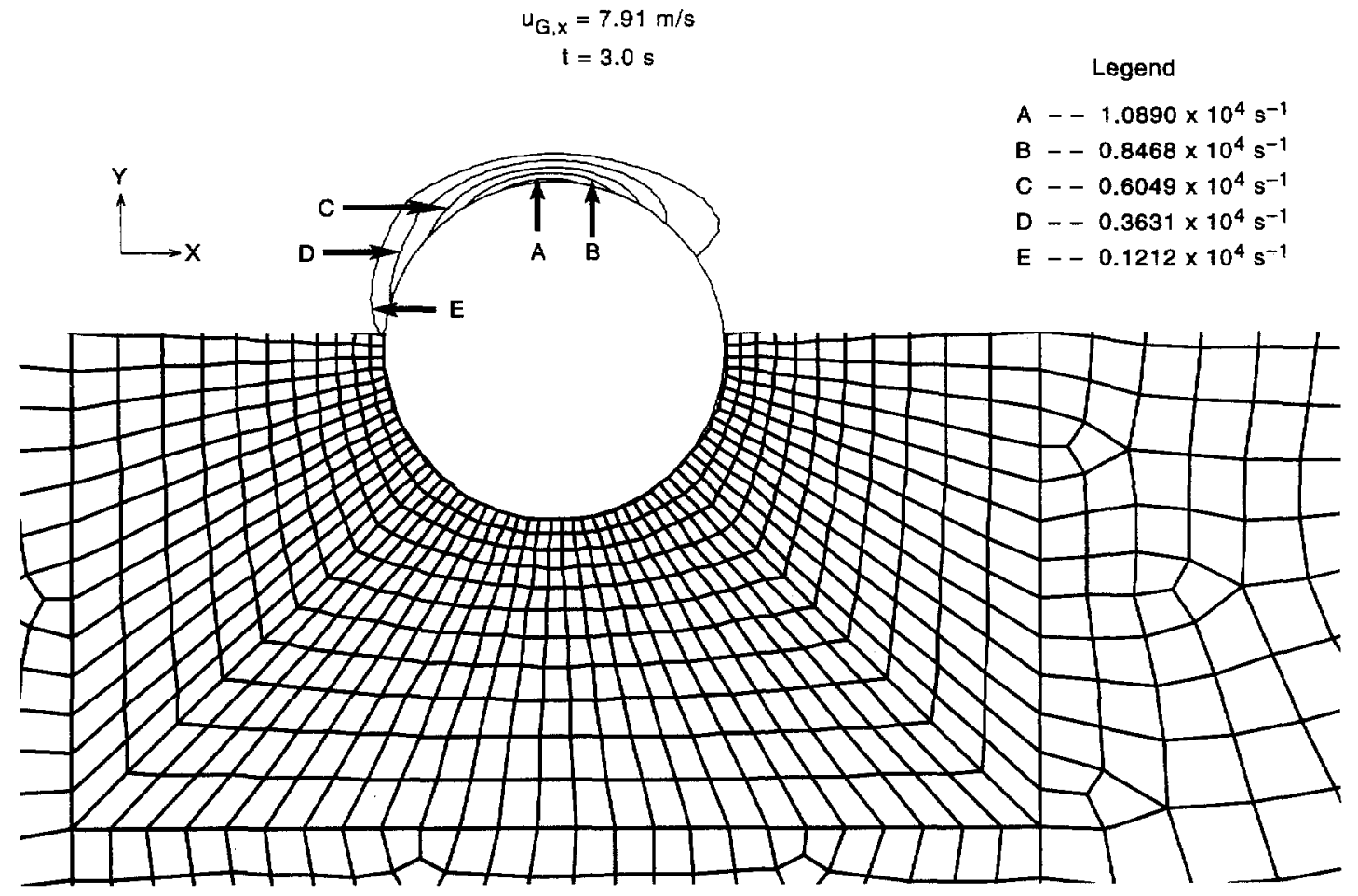

Figure 4. Computed isovorticity contours and part of the computational mesh; $u_{G x}=7.91 \mathrm{~m} / \mathrm{s}$. 


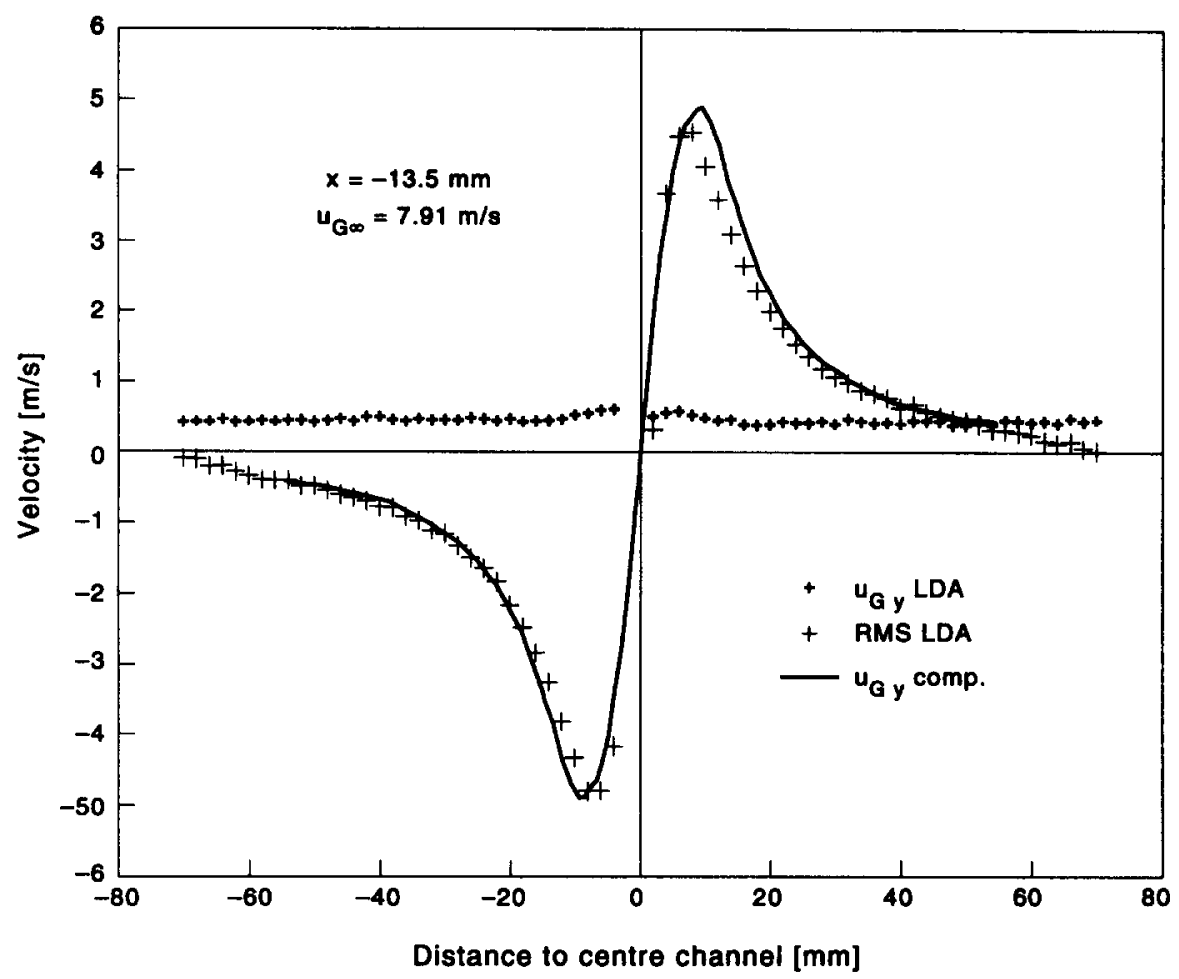

Figure 5. Comparison of measured and computed velocity components in horizontal $(y)$ direction, $1 \mathrm{~mm}$ upstream of the top of the cylinder. RMS indicates the root-mean-square of the fluctuating component. $u_{G \times}=7.91 \mathrm{~m} / \mathrm{s}$.

the same analysis as described above. The films have been analyzed with an automated motion analyzer.

Although the measurement frequency is higher, this method has the drawback that it is (even more) time-consuming since at each frame not only the particle position, but also the position of the cylinder has to be determined. The results proved to contain essentially the same information as those obtained with the photocamera.

\section{COMPUTATIONAL}

\subsection{Modeling}

In time-dependent simulations, the continuous phase is described in the Eulerian framework while the dispersed particles are considered from a Lagrangian point of view. The particles are rigid and spherical with mass density $\rho_{\mathrm{p}}$. The equation of motion is

$$
\rho_{\mathrm{p}} \cdot \forall_{\mathrm{p}} \frac{\mathrm{d} \mathbf{u}_{\mathrm{p}}}{\mathrm{d} t}=\mathbf{F}_{\mathrm{D}}+\mathbf{F}_{\mathrm{AM}}+\mathbf{F}_{\mathrm{PG}}+\mathbf{F}_{\text {Basset }}+\mathbf{F}_{\mathbf{L}}+\mathbf{F}_{\text {buo }}
$$

where $\mathbf{u}_{\mathrm{p}}$ is the velocity of the particle and $d \mathbf{u}_{\mathrm{p}} / \mathrm{d} t$ is the rate of change of the velocity of the body. The forces on the RHS of [4] represent, respectively, steady drag, added mass, pressure gradient, Basset history, lift and buoyancy. Most of them have been discussed to some extent in section 1 and the dependencies on the Reynolds and acceleration numbers in particular. Expressions for all the force contributions are given below.

$$
\mathbf{F}_{\mathrm{D}}=C_{\mathrm{D}} \cdot \pi \cdot d_{\mathrm{p}}^{2} \cdot \frac{1}{8} \cdot \rho_{\mathrm{G}} \cdot\left(\mathbf{u}_{\mathrm{G}}-\mathbf{u}_{\mathrm{p}}\right) \cdot\left|\mathbf{u}_{\mathrm{G}}-\mathbf{u}_{\mathrm{p}}\right|
$$

where $\rho_{\mathrm{G}}$ and $\mathbf{u}_{\mathrm{G}}$ represent the mass density and velocity of the air, respectively. The drag coefficient, $C_{\mathrm{D}}$, is given in table 1 . The particle Reynolds number, $\operatorname{Re}_{\mathrm{p}}$, is defined as $d_{\mathrm{p}} \cdot\left|\mathbf{u}_{\mathrm{G}}-u_{\mathrm{p}}\right| / v_{\mathrm{G}}$ with $v$ the kinematic viscosity. Because of the low level of turbulence, $C_{\mathrm{D}}$ does not depend on the turbulent intensity. 
The added mass force is defined as

$$
\mathbf{F}_{\mathrm{AM}}=\rho_{\mathrm{C}}=\forall_{\mathrm{p}} \cdot C_{\mathrm{AM}} \cdot\left(\frac{\mathrm{D} \mathbf{u}_{\mathrm{G}}}{\mathrm{D} t}-\frac{\mathrm{d} \mathbf{u}_{\mathrm{p}}}{\mathrm{d} t}\right)
$$

with

$$
\frac{\mathrm{D}}{\mathrm{D} t}=\frac{\partial}{\partial t}+\mathbf{u}_{\mathrm{G}} \cdot \boldsymbol{\nabla} \quad \text { and } \quad \frac{\mathrm{d}}{\mathrm{d} t}=\frac{\partial}{\partial t}+\mathbf{u}_{\mathrm{p}} \cdot \boldsymbol{\nabla}
$$

see Auton et al. (1988). The pressure gradient force is (Auton et al. 1988):

$$
\mathbf{F}_{\mathrm{PG}}=\rho_{\mathrm{G}} \cdot \forall_{\mathrm{P}} \cdot \frac{\mathrm{D} \mathbf{u}_{\mathrm{G}}}{\mathrm{D} t}
$$

The Basset history force equals (Magnaudet et al. 1995):

$$
\mathbf{F}_{\mathrm{Bassel}}=\frac{3}{2} \cdot d_{\mathrm{p}}^{2} \sqrt{\pi \cdot \rho_{\mathrm{G}} \cdot \mu_{\mathrm{G}}} \cdot \int_{0}^{t}\left(\frac{\mathrm{d} \mathbf{u}_{\mathrm{G}}}{\mathrm{d} t}-\frac{\mathrm{d} \mathbf{u}_{\mathrm{p}}}{\mathrm{d} t}\right) \cdot \frac{\mathrm{l}}{\sqrt{t-\tau}} \cdot \mathrm{d} \tau
$$

with $\mu$ denoting dynamic viscosity. The integral has been calculated as the weighed sum of the relative accelerations in the time interval from $t-30 \Delta t_{\text {comp }}$ to $t, \Delta t_{\text {comp }}$ being $0.1 \mathrm{~ms}$, typically. This procedure necessitated storage of the past relative accelerations and a convenient extrapolation to the acceleration at time $t$. The value 30 has been varied without affecting the final results.

The lift force is given by [1] and has been discussed in section 1. The buoyancy force is $\boldsymbol{g} \cdot \forall_{\mathrm{p}} \cdot\left(\rho_{\mathrm{p}}-\rho_{\mathrm{G}}\right)$ with $\boldsymbol{g}$ the gravitational acceleration.

An analytical solution of [4] is impossible, even if the Basset term is neglected, because of the time dependence of the relative velocities and the accelerations. Computations have, therefore, been performed numerically.

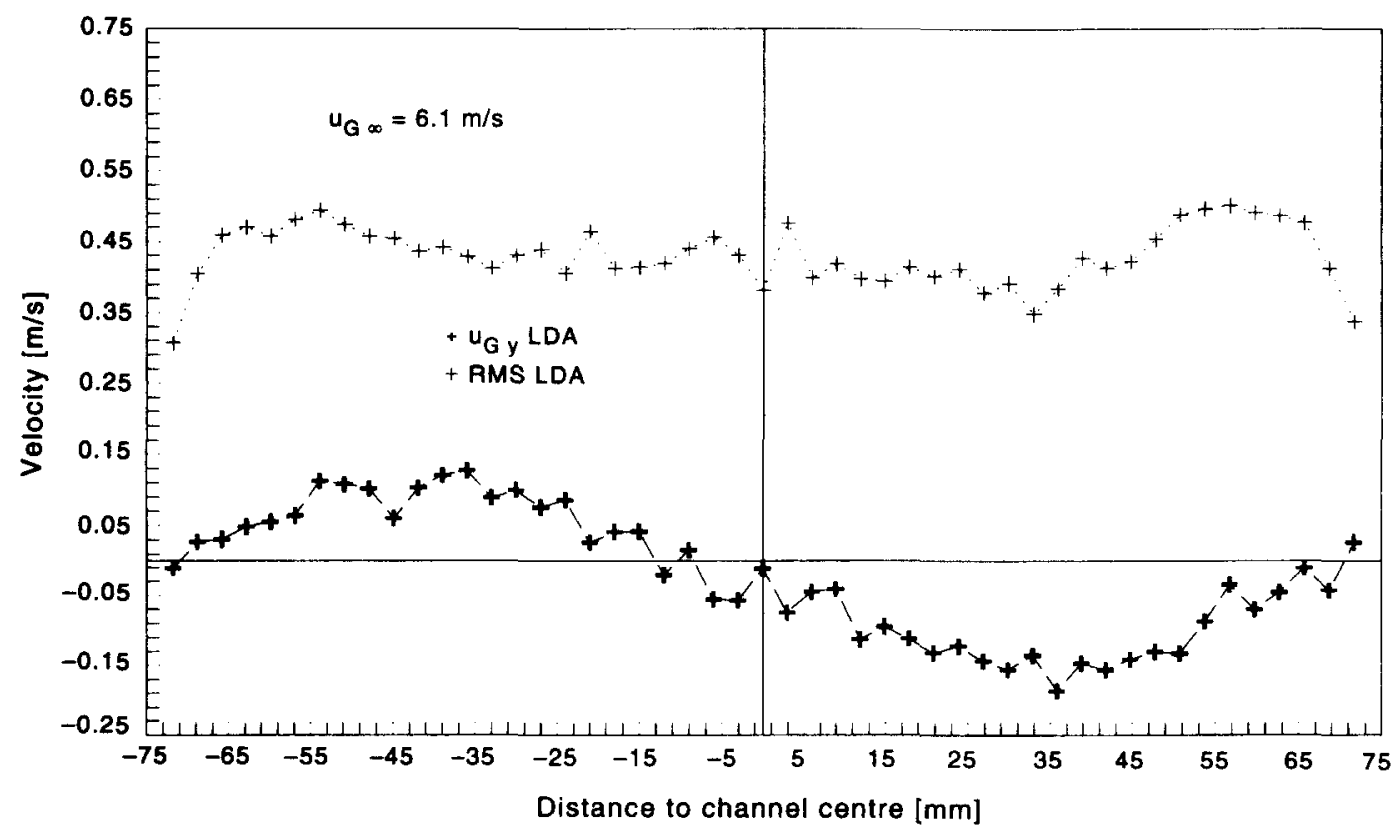

Figure 6. LDA measurements of secondary motion in the gas flow approaching the cylinder at $6.1 \mathrm{~m} / \mathrm{s}$. Velocity components in $y$-direction are shown at a line through the channel centre towards the midpoints of the shortest walls, measured at a height of $115 \mathrm{~mm}$ upstream of the cylinder. See figure 5 for definition RMS. 


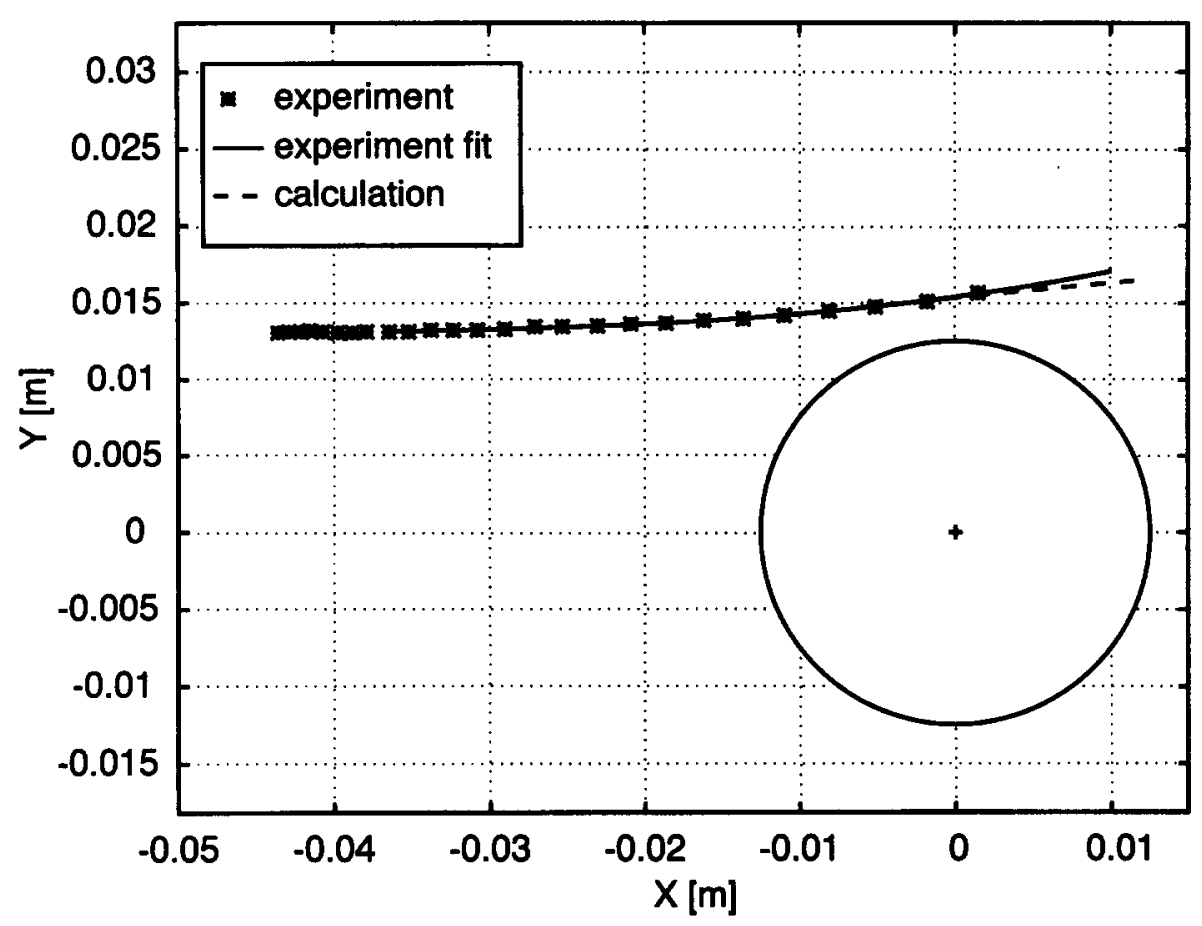

Figure 7. Specimen of measured and predicted particle positions for $u_{\mathrm{G} x}=7.91 \mathrm{~m} / \mathrm{s} . d_{\mathrm{c}}=25 \mathrm{~mm}$; $d_{\mathrm{p}}=2.305 \mathrm{~mm}$; see table 2 for other data of this experiment (under ID 69). $C_{\mathrm{AM}}=1.0 ; C_{\mathrm{L}}$ is given by [3].

\subsection{Numerical}

For the calculations the CFD package FIDAP ${ }^{\mathrm{m}}$, release 7.52, is used. The forces are implemented by means of a special, user-defined subroutine. $\dagger$ The set of ordinary differential equations resulting from the dispersed phase is solved with an explicit classic second-order Runge-Kutta method. For time integration, the implicit first-order backward Euler integrator is applied. More details are given by Engelman (1991).

In the experiments, the air approach velocity, $u_{\mathrm{G} \infty}$, ranged from 2.00 to $7.91 \mathrm{~m} / \mathrm{s}$. Accordingly, the channel Reynolds numbers vary between 11,000 and 44,000 , so the isothermal flow has a turbulent nature. The flow is assumed to be incompressible, which is legitimate since gas velocities are below one third of the Mach number. Equations governing the air flow are those of the standard $k-\epsilon$ model in which the kinetic energy of turbulence, $k$, is connected to the rate of viscous dissipation, $\epsilon$, and the turbulent viscosity, $\mu_{\text {turb }}$, via

$$
\mu_{\text {turb }}=C_{\mu} \cdot \rho_{\mathrm{G}} \cdot k^{2} / \epsilon
$$

Here $C_{\mu}$ is a constant. Other constants appear $\ddagger$ in the dissipative terms of the transport equation of $\epsilon\left(C_{1}\right.$ and $\left.C_{2}\right)$ and in the diffusive terms of the transport equations of $\epsilon\left(\sigma_{\iota}\right)$ and that of $k\left(\sigma_{\mathrm{k}}\right)$.

Each transient simulation requires $50 \mathrm{Mb}$ of memory and 300 time steps to reach pseudo-steady solutions, and takes approximately 6 computation hours on a Silicon Graphics Power-Challenge with 14 MIPS R8000 processors (not all used) at $150 \mathrm{MHz}$. The mesh consists of 3442 elements.

Let RMS denote the root-mean-square of a fluctuating velocity component in a given direction. The turbulent kinetic energy, $k$, is the sum of the squares of the RMS-value of each component $(x, y, z)$ and is measured to amount $0.4 \mathrm{~m}^{2} / \mathrm{s}^{2}$, or about $1 \%$ of $u_{\mathrm{G} \infty}^{2}$. In the numerical simulations, $k$ at the inlet has been varied over a considerable range, up to $30 \%$ of $u_{\mathrm{G} \infty}^{2}$ without affecting the converged flow solution near the cylinder. 


\subsection{The velocity field of the gas}

Figure 3 gives an example of a computed gas flow field near the cylinder and figure 4 gives the corresponding vorticity contours. The latter figure shows where the lift force [1] may be expected to contribute: merely in the vicinity of the cylinder. It also shows part of the mesh.

Figure 5 shows a comparison of measured and computed velocity components in the $y$-direction at $1 \mathrm{~mm}$ above the top of the cylinder. The velocity gradients in the $x$-direction are quite large at these locations and the LDA observation volume extends to $0.5 \mathrm{~mm}$ in the $x$-direction, causing an integration of velocities. In addition, the inaccuracy of the positioning of the LDA measuring volume with respect to the cylinder, estimated to be $0.22 \mathrm{~mm}$, induces some errors. The agreement between measurements and predictions is, therefore, acceptable. At other locations a similar agreement between measurements and predictions has been found. At distances from the centre of the channel, exceeding $50 \mathrm{~mm}$, the computed velocity gradients depend on the type of boundary condition: no-slip or entrainment. Both conditions have been applied to examine the effect of the presence of side-walls on fluid motion and particle trajectories. No differences have been found in the gas velocity gradients nor in the particle trajectories near the cylinder.

\subsection{Secondary flows}

Turbulent flow in straight ducts of rectangular cross section is characterized by the presence of secondary flows superimposed upon the primary flow (Naimi and Gessner 1994). In a rectangular duct with lengths $a$ and $b, a>b$, the secondary velocity vectors point towards the wall over a distance of about $a-b / 2$ at the line through the channel centre towards the midpoint of the shortest wall (length $b$ ). The secondary flow at this line has been measured to amount little more than $1 \%$ of $u_{\mathrm{G} x}$, see figure 6 , at those places where the particles are injected. It was, therefore, unnecessary to perform 3 -D computations of the gas flow. The gas flow around the cylinder has

Table 2. Specimen of table with experimental data. The other eight tables are available on request. $a_{1}-a$ are polynomial fit coefficients to find $y$-locations for $x$-values; $R$ is the $R$-value of the fit. $x 1-x 26$ are the measured $x$-positions in mm of the particle. $d_{1}$ is the particle diameter in mm. $x i$ is the number of the particle position used as the starting point for computations

\begin{tabular}{|c|c|c|c|c|c|c|c|c|c|c|}
\hline & ID 62 & ID 63 & ID 64 & 1065 & ID 66 & ID 67 & ID 68 & ID 69 & ID 70 & ID 71 \\
\hline$a_{0}$ & 15.194 & 13.692 & 14.2698 & 15.315 & 15.751 & 14.462 & 16.015 & 15.3845 & 14.4778 & 12.6927 \\
\hline$a_{1}$ & 0.1563 & 0.1211 & 0.1154 & 0.1607 & 0.1579 & 0.1265 & 0.1347 & 0.136 & 0.1676 & 0.0375 \\
\hline$a=$ & 0.0026 & $33.8 \times 10^{4}$ & $28 \times 10^{4}$ & $14 \times 10^{4}$ & $25.5 \times 10^{4}$ & $35.6 \times 10^{4}$ & $14.3 \times 10^{+}$ & $28.4 \times 10^{4}$ & $23.8 \times 10^{2}$ & $17.9 \times 10^{4}$ \\
\hline$a_{3}$ & $22 \times 10^{5}$ & $38 \times 10^{t}$ & $21 \times 10^{0}$ & $7.5 \times 10^{4}$ & $2 \times 10$ & $37 \times 10^{4}$ & $5.16 \times 10^{\circ}$ & $22 \times 10^{0}$ & $2.51 \times 10^{7}$ & $23 \times 10^{n}$ \\
\hline$R$ & 0.9988 & 0.9975 & 0.9937 & 0.9983 & 0.9959 & 0.997 & 0.9982 & 0.998 & 0.993 & 0.9511 \\
\hline$x 1$ & -43.980 & -44.040 & -43.406 & $\ldots .41 .51$ & 43.87 & .43 .751 & $\cdots 43.291$ & -43.578 & 44.210 & 44.613 \\
\hline$\times 2$ & -42.085 & -42.487 & -42.315 & -40.76 & -42.72 & -43.291 & -41.913 & -42.889 & 43.521 & -43.930 \\
\hline$\times 3$ & -40.765 & -40.880 & -41.396 & -39.22 & -41.57 & -42.028 & -41.052 & -42.085 & -42.602 & -42.717 \\
\hline$x 4$ & -39.905 & -39.790 & -40.306 & -37.84 & -40.08 & -40.765 & -39.733 & -41.568 & -40.937 & -41.568 \\
\hline$\times 5$ & -38.873 & -38.815 & -38.701 & -35.67 & -39.16 & -39.217 & -38.128 & -40.708 & -39.217 & -40.708 \\
\hline$x 6$ & -35.894 & -37.498 & -36.982 & -34.35 & -37.96 & -37.555 & -36.524 & -39.733 & -37.268 & -38.357 \\
\hline$\times 7$ & -34.350 & -35.894 & -35.036 & -32.86 & -36.58 & -35.551 & -34.235 & -38.815 & -35.608 & -36.581 \\
\hline .8 & -32.749 & -34.178 & -33.435 & -31.44 & -35.38 & -33.492 & -32.064 & -37.898 & -34.293 & -35.036 \\
\hline$\times 9$ & -30.922 & -32.064 & -31.093 & -30.07 & -33.49 & -31.264 & -29.894 & -36.467 & -32.6 .35 & -33.092 \\
\hline$\times 10$ & -28.868 & -29.894 & -28.982 & -28.41 & -31.89 & -28.868 & -27.613 & -35.467 & -31.093 & -30.750 \\
\hline 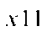 & -26.987 & -27.499 & -26.702 & -26.36 & 29.95 & 26.531 & -25.164 & -33.778 & -29.438 & -28.411 \\
\hline$\times 12$ & -24.823 & -24.994 & -24.254 & -24.31 & -27.90 & --24.026 & 22.662 & 32.349 & -27.670 & -25.734 \\
\hline$\times 13$ & -22.605 & -22.434 & -21.639 & -22.38 & .. 25.73 & -21.411 & -20.048 & -30.807 & -25.677 & -23.060 \\
\hline .14 & -20.332 & -19.765 & -18.913 & -20.05 & $\therefore 23.34$ & -18.630 & -17.382 & -29.079 & -23.628 & -20.219 \\
\hline$\times 15$ & -17.836 & -16.929 & -16.249 & -17.72 & -20.90 & -15.852 & -14.606 & -27.101 & -21.468 & 17.155 \\
\hline$\times 16$ & -15.229 & -13.927 & -13.078 & -15.34 & -18.12 & -12.909 & -11.439 & -25.335 & -19.140 & 14.323 \\
\hline .117 & -12.456 & -10.987 & -10.139 & -12.74 & -15.46 & -9.687 & --8.389 & -23.060 & -16.645 & -10.761 \\
\hline$x 18$ & -9.575 & -7.769 & -6.754 & -10.03 & -12.68 & -6.303 & -4.950 & -20.900 & .. 14.040 & -7.317 \\
\hline$x 19$ & -6.472 & -4.218 & -3.486 & -7.092 & -9.462 & -2.811 & --1.574 & -18.630 & -11.269 & -3.711 \\
\hline$x 20$ & -3.261 & -0.562 & 0.1685 & -4.049 & -6.246 & 0.843 & 2.078 & -16.192 & $\cdot 8.446$ & $\ldots 0.843$ \\
\hline$\times 21$ & 0 & 3.1996 & 3.9285 & -1.012 & -2.811 & & & -13.644 & -5.345 & 2.134 \\
\hline$\times 22$ & 3.648 & & & 2.6947 & 0.730 & & & -10.987 & -1.742 & \\
\hline$x 23$ & & & & & & & & -8.107 & 1.685 & \\
\hline$\times 24$ & & & & & & & & -5.119 & & \\
\hline$\times 25$ & & & & & & & & -1.799 & & \\
\hline$x 26$ & & & & & & & & 1.460 & & \\
\hline$d_{p}$ & 2.361 & 2.361 & 2.192 & 2.024 & 2.024 & 2.136 & 2.136 & 2.305 & 2.024 & 2.361 \\
\hline $\mathbf{u}_{\mathrm{s}}$ & 7.91 & 7.91 & 7.91 & 7.91 & 7.91 & 7.91 & 7.91 & 7.91 & 7.91 & 7.91 \\
\hline$x i$ & 10 & 6 & 9 & 10 & 11 & 7 & 8 & 9 & 12 & 7 \\
\hline$x_{11}$ & -28.868 & -37.498 & -31.093 & -28.41 & -29.95 & -35.551 & 32.064 & -36.467 & -27.670 & -36.581 \\
\hline$l^{1}$ & 7.556 & 11.900 & 12.757 & 11.708 & 12.772 & 12.802 & 12.996 & 13.135 & 11.657 & 12.590 \\
\hline$u$ & 0.7524 & 0.6865 & 0.8445 & 0.8206 & 0.8212 & 0.8235 & 0.8678 & 0.5036 & 0.7975 & 0.6180 \\
\hline$v_{0}$ & 0.0467 & 0.01584 & 0.0036 & 0.0545 & 0.0505 & 0.00784 & 0.0552 & 0.00804 & 0.0317 & $-24 \times 10$ \\
\hline
\end{tabular}




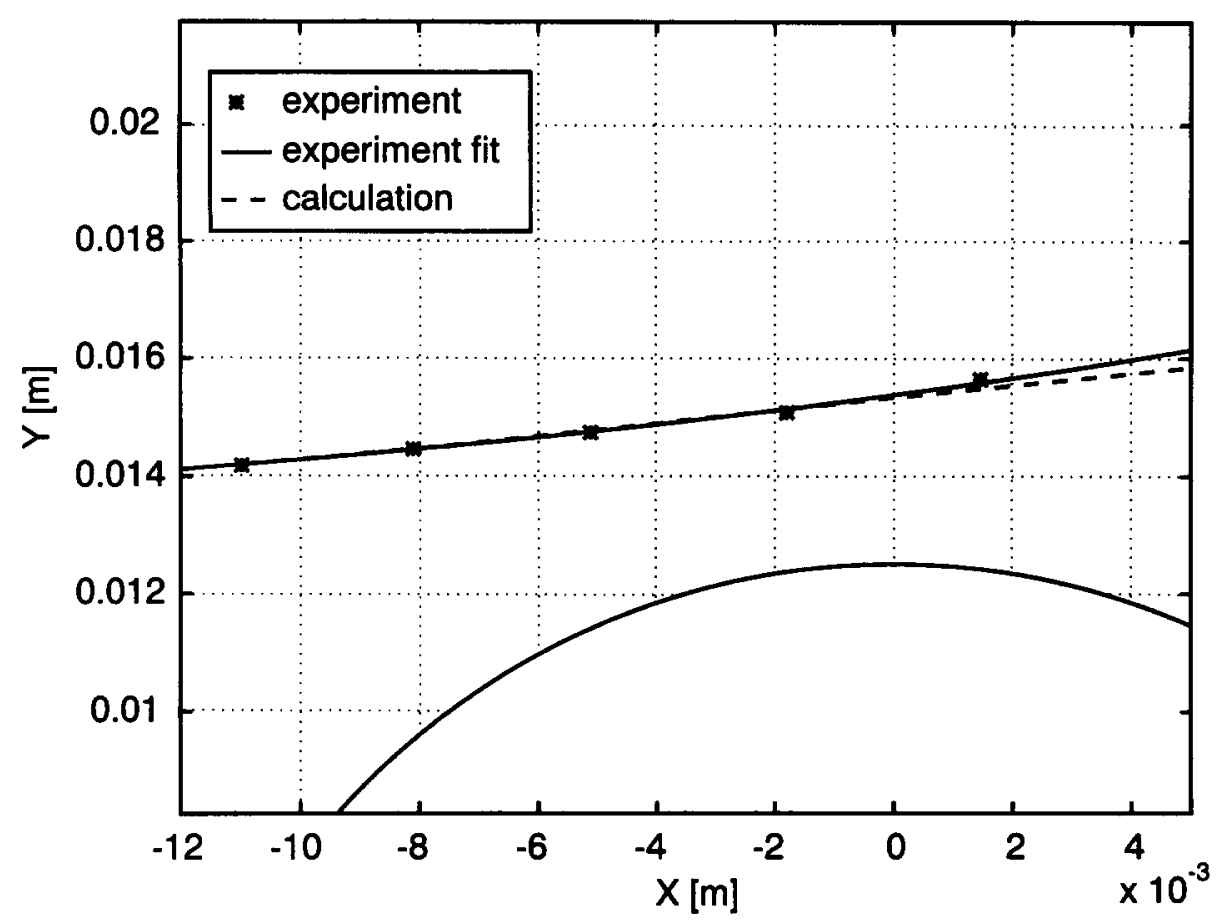

Figure 8. Close-up of the trajectories of figure 7.

been modeled 2-D, and the measured secondary velocity components have been added to the computed velocity components in the $y$-direction, in the procedure to compute the acceleration of the particles. This adding of the secondary motion to the primary gas flow has been found not to affect the computed particle trajectories. This is the case because of the presence of velocity components in the $y$-direction as large as $50 \%$ of $u_{\mathrm{G} x}$ in the vicinity of the cylinder, see figure 5 .

It is noted that systematic errors can arise in the measurement of the secondary mean velocities from an error in the orientation angle of the normal to the anemometer fringe pattern (Melling and Whitelaw 1976). This experimental difficulty accounts for the slight asymmetry observed in figure 6. It also accounts for the low resolution near the shortest channel wall. The velocity is there expected to change sign at distance $a-b / 2$ from the channel centre, as discussed above, but due to the low resolution this is not discernable in the measurements. The resolution in the $x$-direction is much better since the velocity components in this direction are much higher.

\subsection{Turbulence and particle motion}

The particle relaxation time, $\tau_{\mathrm{p}}$, which is the time needed to acquire $63 \%$ of the velocity of an eddy, is large, of the order of $2 \mathrm{~s}$ since

$$
\tau_{\mathrm{p}} \approx \rho_{\mathrm{p}} \cdot d_{\mathrm{p}}^{2} /\left\{18 \mu_{\mathrm{G}}\left(1+f\left(\overline{\operatorname{Re}}_{\mathrm{p}}\right)\right\}\right.
$$

if $C_{\mathrm{D}}$ is written as $24\left(1+f\left(\overline{\mathrm{Re}_{\mathrm{p}}}\right) / \overline{\mathrm{Re}_{\mathrm{p}}}\right.$, see table 1 , and $\overline{\mathrm{Re}_{\mathrm{p}}}$ is a Reynolds number averaged over the trajectory considered. The relaxation time will now be seen to exceed the eddy lifetime, $T_{\mathrm{c}}$, considerably in all cases and also the time needed for the particle to traverse the eddy, $T_{1}$, in most cases. Turbulence is, therefore, expected not to affect the motion of the particles. This is confirmed by computations with FIDAP ${ }^{\mathrm{tm}}$ with a simple stochastic model based on the work of Gosman and Ioannides (Engelman 1991). The particle diffusivity decreases roughly proportional to $1 / \tau_{\mathrm{p}}$, see Hunt et al. (1994).

The characteristic eddy length, $L_{\mathrm{e}}=c_{\mu}^{3 / 4} \cdot k^{3 / 2} / \epsilon$, is about $1 \mathrm{~mm}$ indicating that the largest eddies have about the same size as the particles. The eddy lifetime is usually estimated as $L_{\mathrm{c}} / \sqrt{2 k / 3}$ or $0.16 \mathrm{k} / \epsilon . T_{\mathrm{e}}$ is 1 or $2 \mathrm{~ms}$, typically, which is only one order of magnitude less than the time of flight of the particle through the observed space but still three orders of magnitude less than $\tau_{\mathrm{p}}$. 

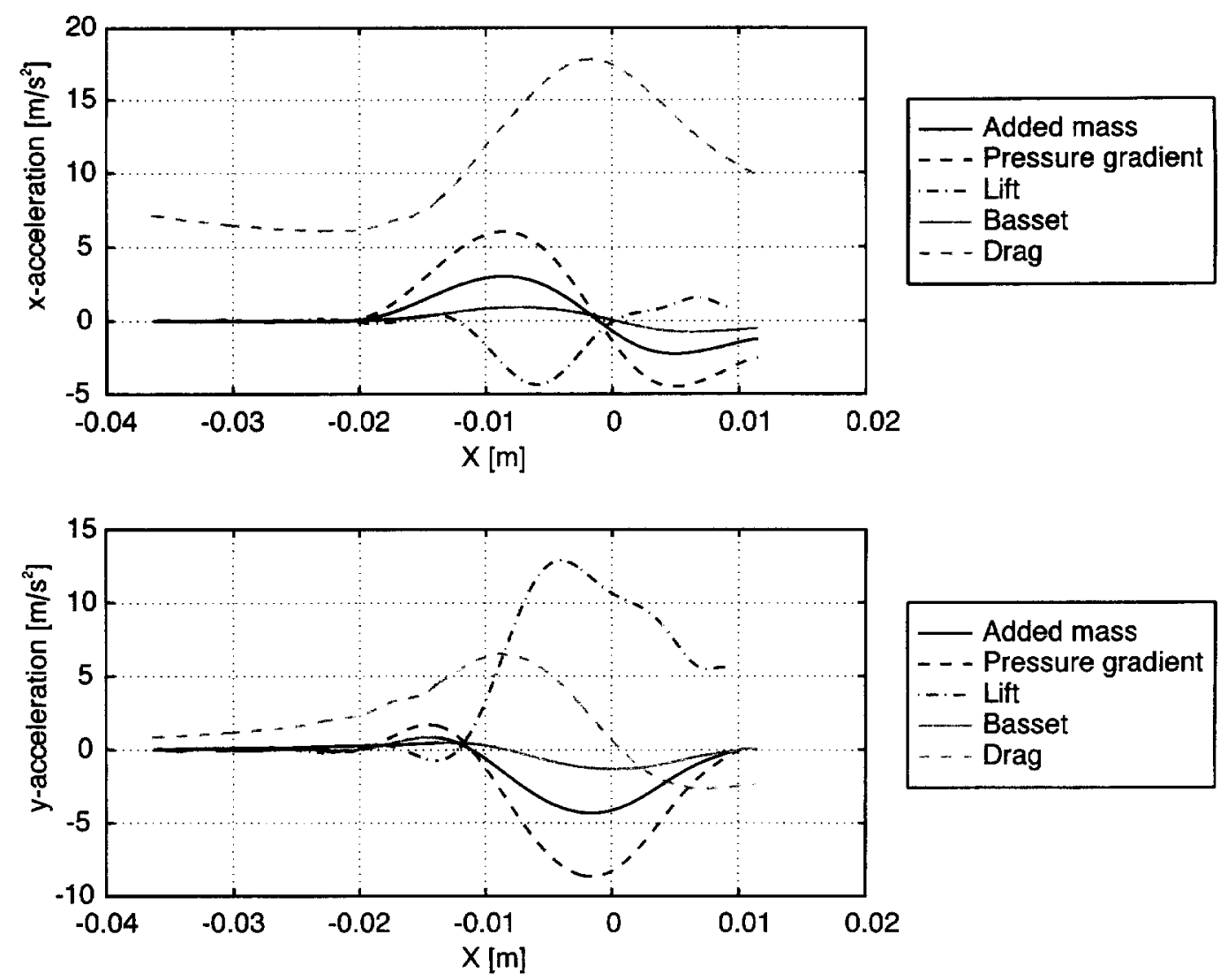

Figure 9. The acceleration components of the particle of figure 7.

The relative velocity between particle and turbulent eddies, $\left|\mathbf{u}_{\mathrm{i}}-\mathbf{u}_{\mathrm{p}}\right|$, is at high gas velocities of the order of $4 \mathrm{~m} / \mathrm{s}$. The time for the particle to traverse an eddy,

$$
T_{1} \approx-2 \cdot \ln \left(1-\frac{L_{\mathrm{e}}}{\tau_{\mathrm{r}} \cdot\left|\mathbf{u}_{\mathrm{c}}-\mathbf{u}_{\mathrm{r}}\right|}\right)
$$

is then about $0.04 \mathrm{~ms}$, which is much too short for the particle to reach the peak fluid velocity, implying that the particle enters another eddy way before it has adopted the speed of the last one. Only at $u_{\mathrm{i}} \approx 2 \mathrm{~m} / \mathrm{s}$ the relative velocity is small enough for the particles to have a significant transit time as compared to $\tau_{\mathrm{p}}$.

Near the injection point the values of $k$ and c are, of course, larger than the ones used in the above estimates for the undisturbed gas flow approaching the cylinder. The measurements show that turbulent eddies created at the injection capillary affect the particle motion directly after injection for $u_{\mathrm{G}},<2 \mathrm{~m} / \mathrm{s}$, indeed. This has, however, no effect on the results described below.

\section{RESULTS AND ANALYSIS}

A typical measurement and computational result for $u_{\mathrm{i},},=7.91 \mathrm{~m} / \mathrm{s}$ is shown in figure 7 . For the computed trajectory, [1] and $C_{\mathrm{L}}$ given by [3] have been used. Since the wake of the cylinder is essentially transient, only transient gas flow computations are performed. Upstream of the center, i.e. at $x<0$, a steady-state solution is obtained. Varying the starting time of the particle injection in the flow did, therefore, not affect the predicted trajectories in the flow area considered.

To increase the accuracy of the simulation, the initial conditions have been determined from the 

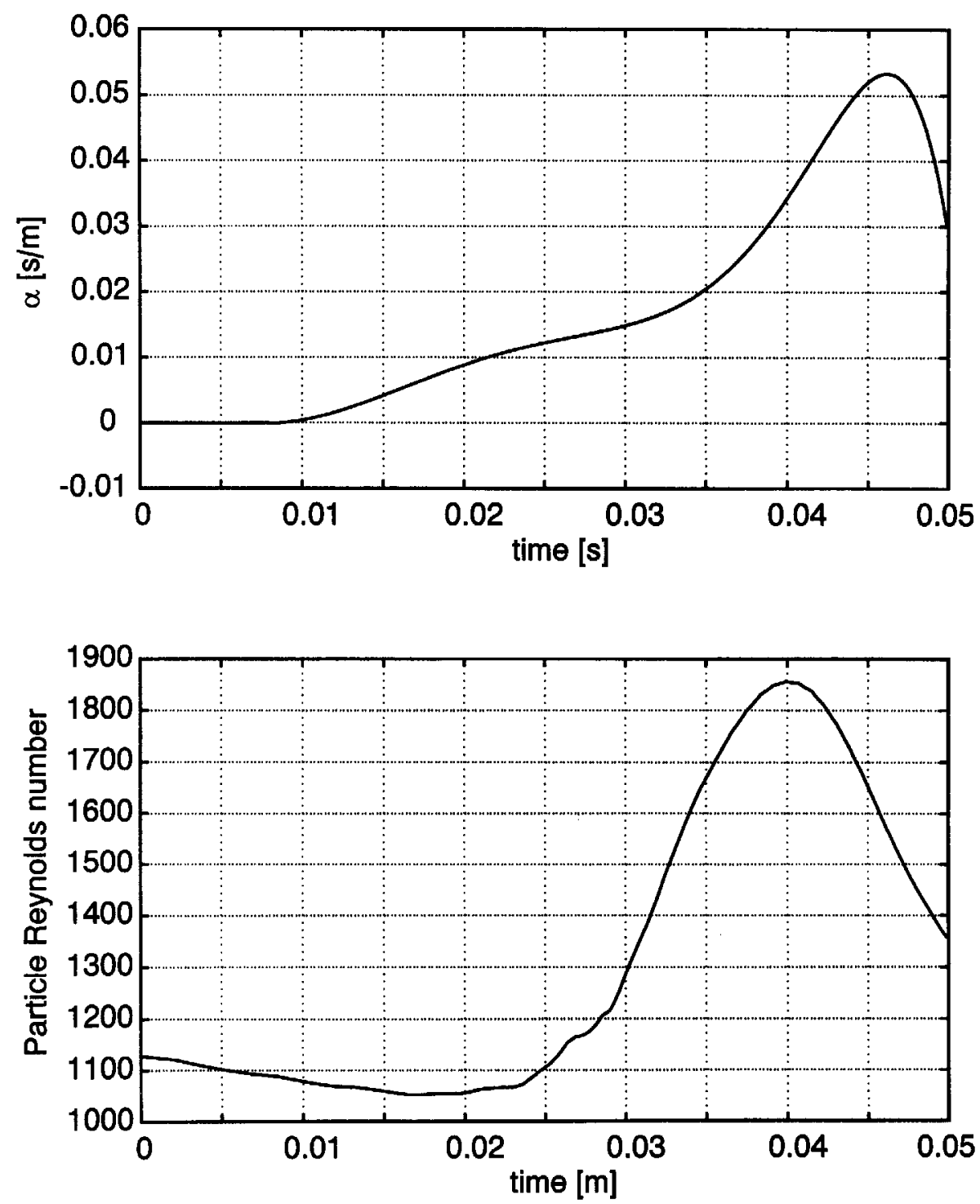

Figure 10. The variation of the particle Reynolds number and of the shear number, $\alpha$, for the trajectory of figure 7 .

experiments by first fitting a third-order polynomial through the experimental points, see the solid line in figure 7. A starting point with $x$-coordinate $x_{0}$ is selected out of the set of experimentally observed locations satisfying the requirements that path oscillations are minimal and that the fitting curve is nearly parallel to the $x$-axis. The next observed particle location is reached after time $\Delta t=1 / t_{\text {strob }}, t_{\text {strob }}$ being the frequency of the stroboscope. At this time, the fitting procedure yields the displacements $\Delta x$ and $\Delta y$. The program FIDAP ${ }^{\mathrm{tm}}$ yields the initial acceleration, $a_{0}$, which is used to estimate the initial velocity component in $x$-direction, $u 0$ via:

$$
u 0=\frac{\Delta x}{\Delta t}-\frac{1}{2} a_{0} \cdot \Delta t
$$

The initial velocity component in $y$-direction, $v 0$, follows similarly. Table 2 summarizes some typical results of this procedure. The initial velocity component, thus established, yield quite good agreement between measured and computed trajectories, see also figure 8 .

The histories of the individual acceleration components on the particle of figure 7 are shown in figure 9 . In the $x$-direction, gravity (not shown since it is a constant) and drag dominate and 
are of almost equal importance. In the $y$-direction, the drag and pressure gradient forces dominate, although the added mass force is quite significant. The reason for the importance of the added mass has been explained in section 1 and is essentially the way the experiment has been set up. Near the cylinder, the air velocity increases to more than $150 \%$ of its approach-value and alters direction, see figures 3 and 5, whereas the fairly large, heavy particle can not respond to the flow changes as quickly. In addition, the particle is injected at zero speed, while the transit time $(\approx 60 \mathrm{~ms})$ is much less than the average relaxation time $(\approx 2 \mathrm{~s}$, see section 3.5$)$. This creates high relative velocities, high particle Reynolds numbers, see figure 10 , and high relative accelerations.

The effect of the individual force contributions on particle trajectory computations is illustrated in figure 11; the effect of $C_{\mathrm{L}}$ will be discussed below. At the height of the cylinder axis, at $x=0$, the inclusion of only drag and gravity yields a predicted $y$-location that differs $0.5 \mathrm{~mm}$ with the $y$-location predicted if all other, 'extra', forces are included as well. The difference is even larger if the two trajectories are compared that correspond to all forces except lift and to all forces including lift. Since the measurement accuracy is $0.04 \mathrm{~mm}$, see section 2 , the extra forces can not be neglected. Figure 11 shows that even the neglection of only the added mass or only the pressure gradient force leads to detectable differences, in accordance with the above conclusions of figure 9.

As figure 9 shows, the accelerations induced in the $y$-direction by the extra forces except the Basset force are large enough to justify the fitting of force coefficients. The added mass coefficient, $C_{\mathrm{AM}}$, can not be adapted since

- this would lead to unacceptable discrepancies between measured and predicted particle positions upstream of the cylinder. See also figure 9.

- the value 0.5 is a well-established added mass coefficient for spheres, see section 1.

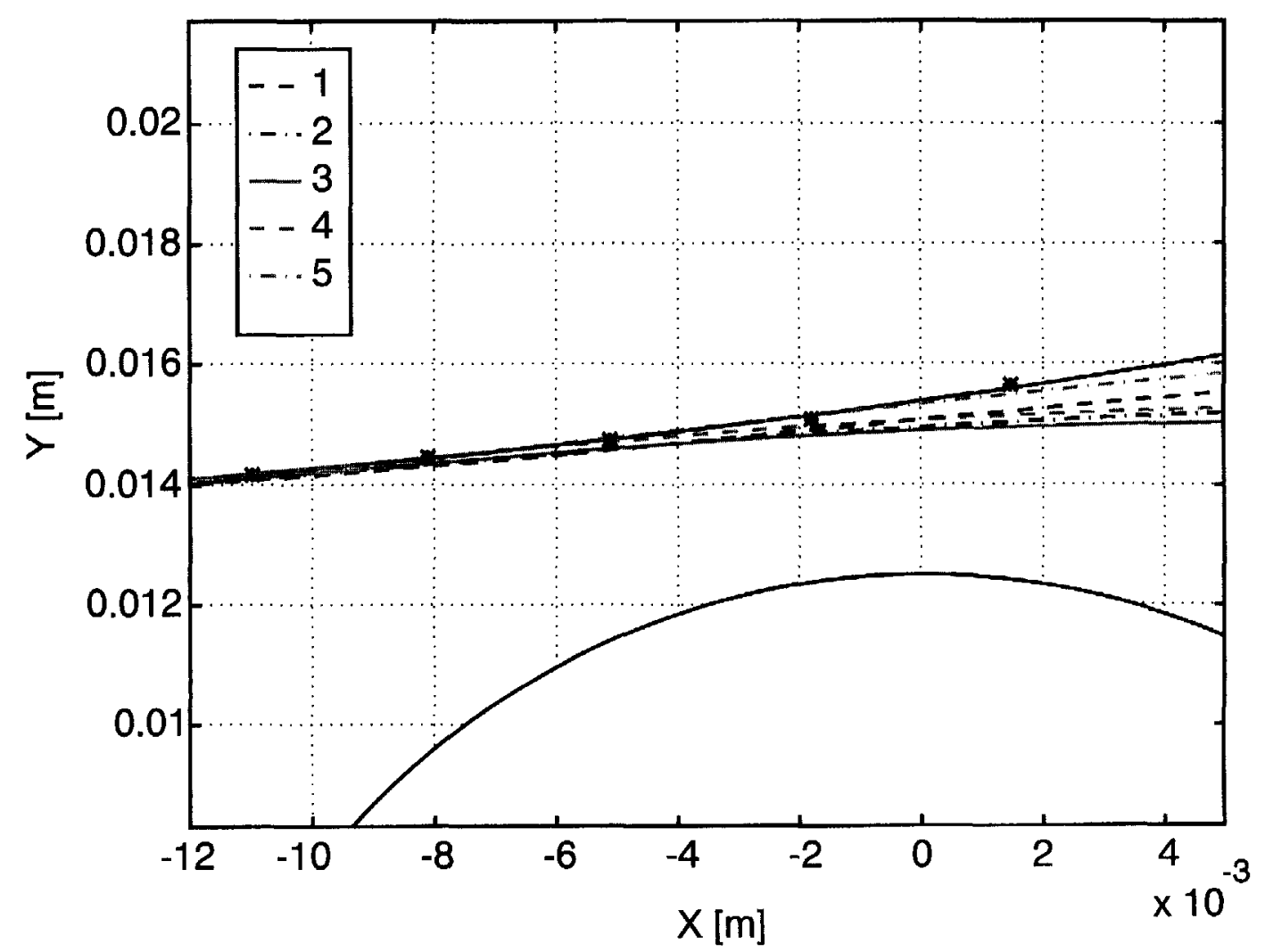

Figure 11. Comparison of computated trajectories for the particle of figure 7. (1) Gravity + drag: (2) gravity + drag + pressure gradient: (3) gravity + drag + pressure gradient + added mass; (4) all forces, $C_{1}=0.5 ;(5)$ all forces, $C_{1}$ given by $[3]$. 


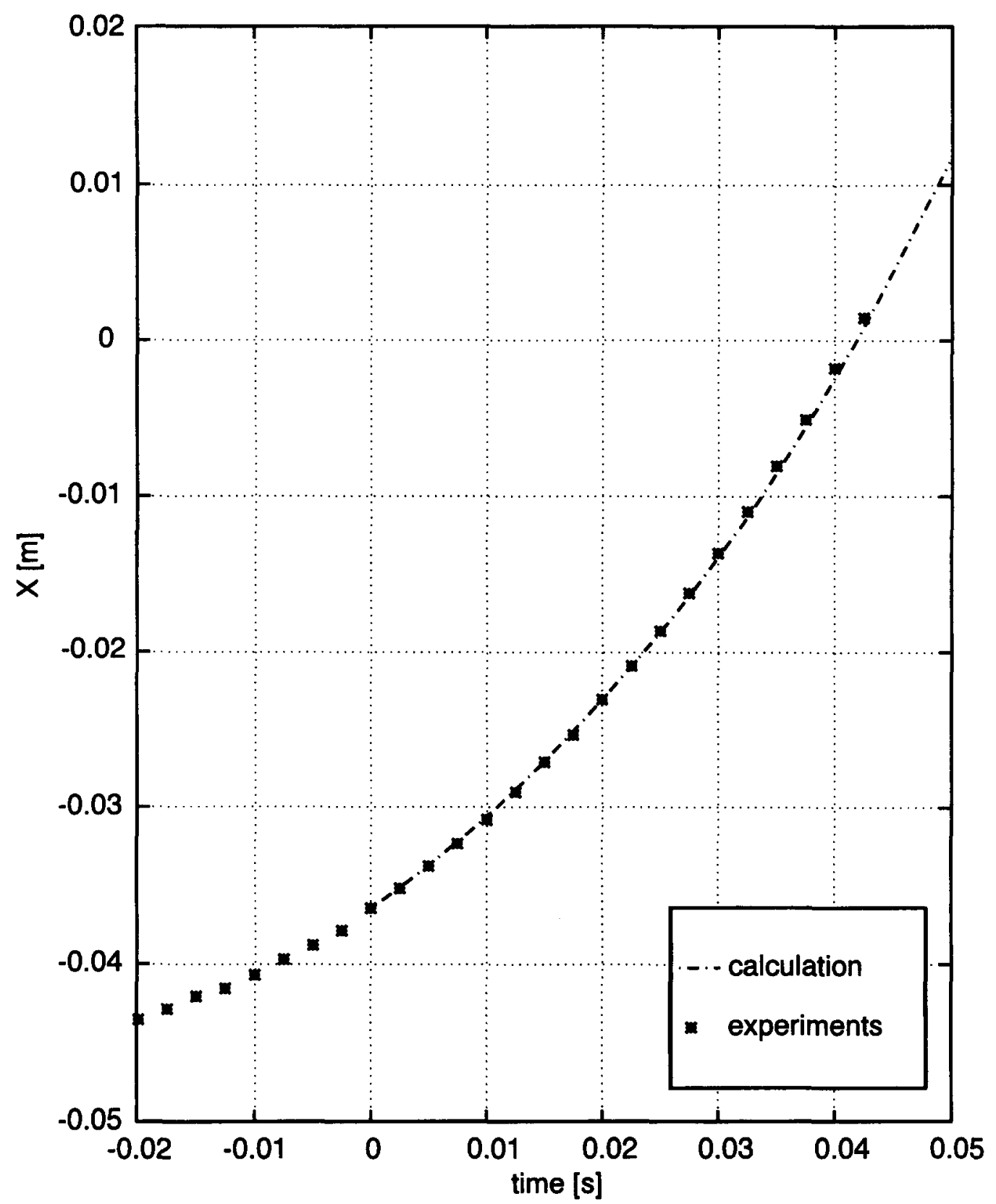

Figure 12. Comparison of predicted and measured histories of $x$-locations to examine the drag force coefficient for the trajectory of figure 7 . The calculation has been performed with the values of table 1 .

The following procedure has been applied to the 20 experiments with $u_{\mathrm{G} \infty}=7.91 \mathrm{~m} / \mathrm{s}$ in order to fit $C_{\mathrm{D}}$ and $C_{\mathrm{L}}$.

(i) A trajectory is computed with the $C_{\mathrm{D}}$ as given in table 1 and $C_{\mathrm{L}}=0.5$ as given below [2].

(ii) The measured and predicted $x$-locations are plotted as a function of time, see the example of figure 12 , and the deviation, $\mathrm{DEV}_{x}$, as defined by

$$
\mathrm{DEV}_{x} \stackrel{\text { def }}{=} \sqrt{\frac{1}{M} \sum_{i}^{M}\left|x_{\text {computed }}(i)-x_{\text {measured }}(i)\right|^{2}}
$$

is computed. Here $i$ numbers the experimentally observed particle locations and $M$ is a natural number. 
(iii) $C_{\mathrm{D}}$ is varied and steps (i) and (ii) are repeated until $\mathrm{DEV}_{x}$ is less than a set-value.

(iv) $C_{\mathrm{L}}$ is varied until $\mathrm{DEV}_{\mathrm{r}}$ is less than a set-value; $\mathrm{DEV}_{v}$ is defined similarly as $\mathrm{DEV}_{s}$. Only the experimental locations near the cylinder have been used to determine $\mathrm{DEV}_{r}$, since only at these locations the vorticity is significant, see figure 3. Differences between measured and predicted $y$-locations turn out to be less than the measurement accuracy $(0.04 \mathrm{~mm})$.

Because of the minor contribution of the lift force to the acceleration in the $x$-direction, see the example of figure 9, repeating of steps (iii) and (iv) turned out not to be necessary. The program MATLAB $^{\mathrm{tm}}$ has been used to facilitate the above fitting procedure. The accuracy of the fitting procedure is not merely the standard deviation of differences between the measured and predicted trajectories of a single particle, but is better since twenty trajectories of identical particles are analyzed.

The results of the fitting procedure are the following. It is unnecessary to adapt the drag coefficient. The comparison of measured and predicted particle trajectories for $u_{\mathrm{G} x}=6 \mathrm{~m} / \mathrm{s}$ yields the same result. The drag coefficient correlations of table 1 are, therefore, found to be appropriate, as expected. In addition it is concluded that the relative velocity is determined quite accurately. The fitting procedure for $u_{\mathrm{G} x}=7.91 \mathrm{~m} / \mathrm{s}$ yields $C_{\mathrm{L}}$-values of about 5 if no $\alpha$-dependence is assumed. Upstream of the center of the cylinder, i.e. for $x<0, \alpha$ is less than 0.04 , and the correlation of Sridhar and Katz (1995), [3] yields good agreement between measured and predicted trajectories. Further downstream, $\alpha$ is higher, see figure 10, and the correlation [3] yields too low a value for $C_{\mathrm{L}}$ if predictions and measurements are compared. This is further discussed below.

To measure the spin velocity, some of the $2 \mathrm{~mm}$ particles have been marked with two concentric rings of a dye in such a way that the particle orientation is clear, whatever the viewing angle is, as long as it does not rotate around the center axis of the two rings. Ten of such measurements showed that the particles did not rotate before coming near the cylinder, i.e. at $x<-0.5 d_{\mathrm{c}}$. In the vicinity of the cylinder, some weak rotation is visible, although never a full rotation cycle was
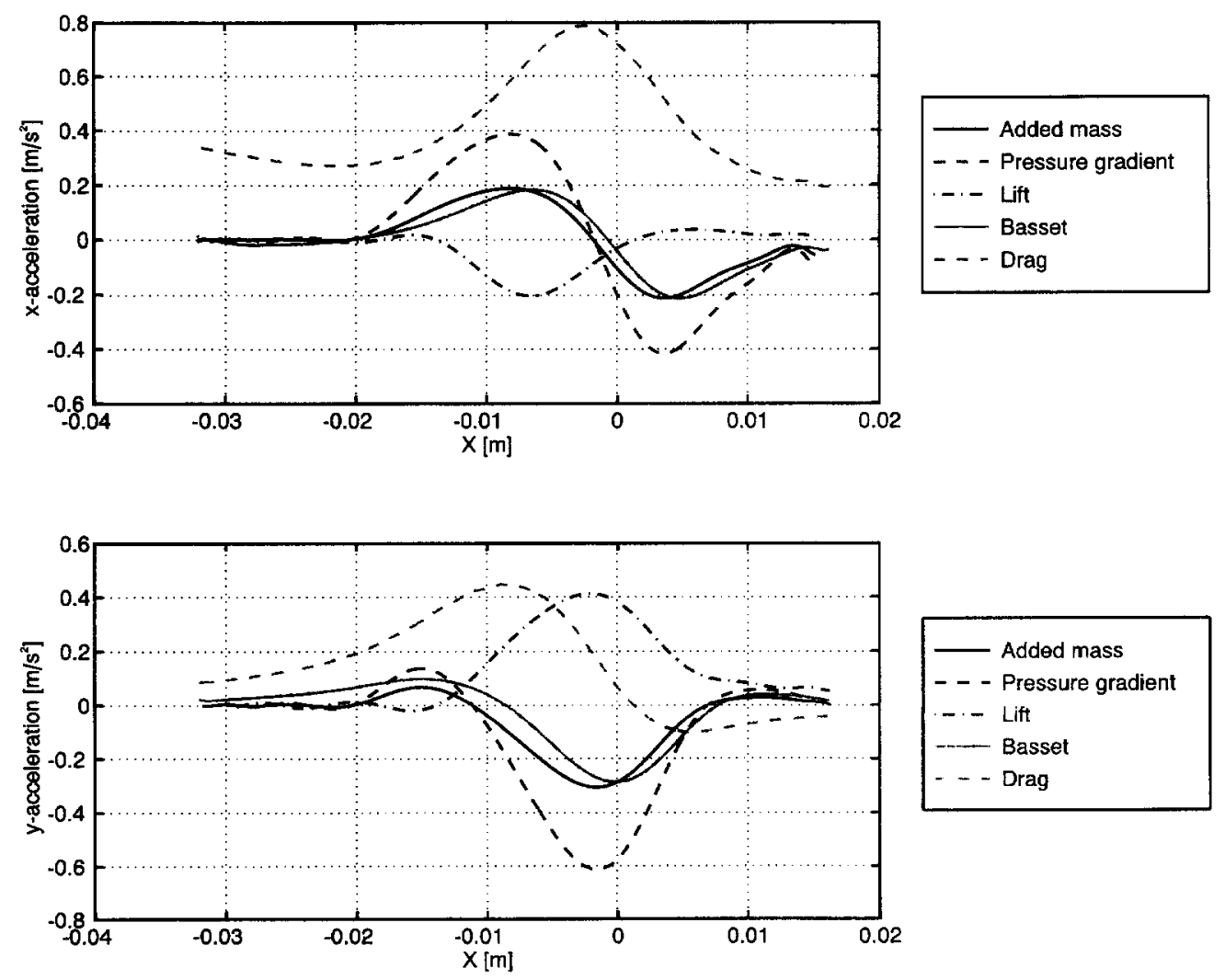

Figure 13. The acceleration components of a particle with $d_{\Gamma}=2.160 \mathrm{~mm}$ for $u_{\omega},=2 \mathrm{~m} / \mathrm{s}$ and $d_{c}=25 \mathrm{~mm}$. $C_{\mathrm{L}}$ is given by [3]. 

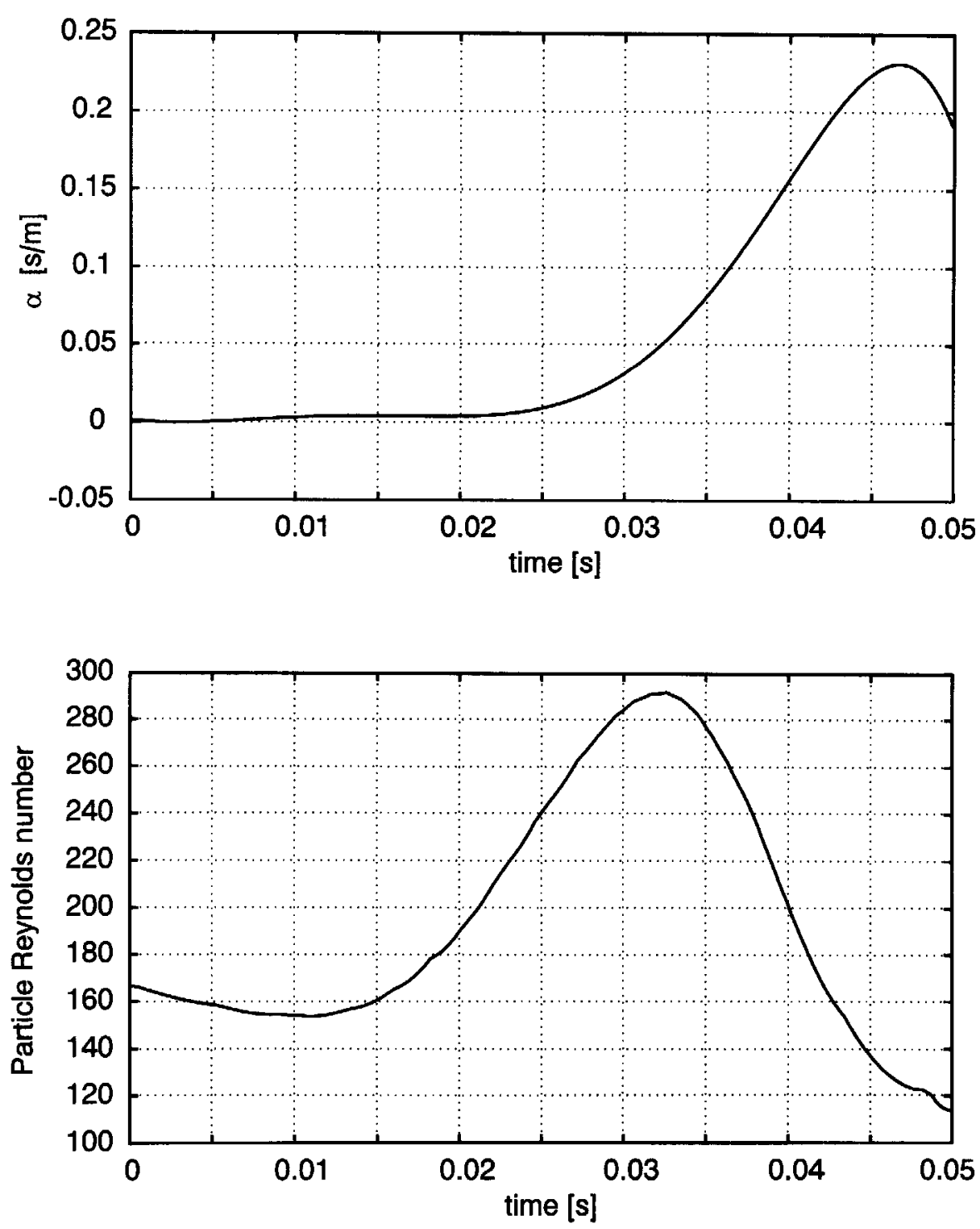

Figure 14. The variation of the particle Reynolds number and the shear number, $\alpha$, for the trajectory of figure 13.

reached during the time-of-flight. This shows that the zero-rotation assumption of Kim et al. (1993) and the zero-shear-stress hypothesis of Auton (1987) are not fulfilled, and that deviations from $C_{\mathrm{L}}=0.5$ are to be expected.

Let the Reynolds number $\operatorname{Re}_{c}$ be based on $d_{c}$, the cylinder diameter, and on $u_{\mathrm{G} \alpha}$. For $\operatorname{Re}_{\mathrm{c}}$ exceeding $10^{4}$ and for particle Reynolds numbers, $\mathrm{Re}_{\mathrm{p}}$, in the range 1500 to 2000 the measurements differ systematically from the predictions in the part downstream of the cylinder axis, i.e. for $x>0$. The particle moves further away from the cylinder than predicted with the aid of all known force components and $C_{\mathrm{L}}$ given by [3]. This is shown in figure 8 for the gas velocity $7.91 \mathrm{~m} / \mathrm{s}$ but is also discernable in the results for $6.0 \mathrm{~m} / \mathrm{s}$. Tuning of $C_{\mathrm{D}}$ and $C_{\mathrm{AM}}$ is out of the question for reasons explained above. If $C_{\mathrm{L}}$ is used as a lumped parameter that accounts for all physical phenomena causing lift on a particle moving in the vicinity of a cylinder, it would have to exceed the values given by the correlation of [3] for $\alpha>0.04$ in order to give good agreement between measured and predicted trajectories. It is, however, possible that this additional lift at $x>0$ is due to the cylinder affecting the wake of the particle, see section 1 and the computations of, e.g. Kim et al. (1993). Since this is another physical phenomenon, it should preferably not be accounted for in the $C_{\mathrm{L}}$-expression [1] that was derived for freely moving particles. Another expression, possibly with 
a dependency on the separation distance, would have to be derived instead. This is beyond the scope of the present study.

The correlation [3] of Sridhar and Katz (1995) gives good results for the relatively large part of the trajectory where the particle moves freely. The present measurements, therefore, substantiate the validity of [3] for freely moving, rigid particles with $\alpha<0.04$.

Comparison of the trajectories for $u_{\mathrm{G} x}=8.0 \mathrm{~m} / \mathrm{s}$ with the 23 experiments at $u_{\mathrm{G} x}=6.0 \mathrm{~m} / \mathrm{s}$ shows that the lower the gas velocity, the less curved the trajectory. At $u_{\mathrm{G} x}=2 \mathrm{~m} / \mathrm{s}$, the measurements and predictions are in very good agreement and both show a straight particle trajectory. This is easily understood if the acceleration components are compared with those due to gravity, see figure 13. They are less by an order of magnitude, at least. The drag force is the largest, but is small because of the low particle Reynolds numbers, see figure 14 .

The 'extra' forces, other than gravity and drag, all have the same order of magnitude. This seems interesting because of the importance of the Basset history force relative to the other "extra' forces. However, almost the same particle trajectory has been computed after omitting the Basset force while retaining all the other forces. For all $\mathrm{Re}_{\mathrm{c}}$-cases considered, the Basset force can, therefore, be omitted without affecting the results.

It is obvious that higher gas accelerations and higher $\mathrm{Re}_{\mathrm{p}}$-values are needed for the assessment of the extra forces. For this reason the 38 experiments at $u_{\mathrm{G},}=2$ and $4 \mathrm{~m} / \mathrm{s}$ have not been used to fit force coefficients. Good agreement between measurement and predictions has been obtained for these cases, with $C_{\mathrm{D}}$ as given by table 1 and $C_{\mathrm{L}}$ given by [3].

\section{CONCLUSIONS}

Trajectories have been measured and computed of rigid spheres with a diameter of $1-2 \mathrm{~mm}$ in downward gas flow near a solid cylinder with a diameter, $d_{c}$, of $25 \mathrm{~mm}$. The Reynolds number based on $d_{\mathrm{c}}$ has been varied from 3000 to 13,000 which is in the subcritical regime. A two-dimensional flow situation has been created with particles injected at a point ca. $45 \mathrm{~mm}$ above the cylinder centre and at ca. $d_{c} / 2$ distance to the vertical through it. The particle Reynolds number, $\mathrm{Re}_{\mathrm{n}}$, based on the relative velocity $\left|\mathbf{u}_{\mathrm{O}}-\mathbf{u}_{\mathrm{p}}\right|$, ranges from 0 to 2000 and varies on a trajectory. The shear number, $\alpha=0.5 d_{\mathrm{p}} \cdot \omega /\left|\mathbf{u}_{\mathrm{G}}-\mathbf{u}_{\mathrm{p}}\right|$, was less than 0.06 which is less by an order of magnitude than other solid sphere measurements of the literature. Comparison of measurements and predictions shows that

(i) Although the gravitational and drag forces are dominant, the pressure gradient and added mass forces have the same order of magnitude as the drag force near the cylinders and can not be neglected. At $u_{\mathrm{G} x}>5 \mathrm{~m} / \mathrm{s}$ they even possess the same order of magnitude in the vicinity of the cylinder.

(ii) If an expression like the classical Basset history force is retained, it does not contribute when the other forces are significant. Although at a gas velocity of $2 \mathrm{~m} / \mathrm{s}$ the history force has the same order of magnitude as the added mass force, it can safely be neglected even in this case, as long as gravity is active.

(iii) The correlation [3] that Sridhar and Katz (1995) found for the lift coefficient, $C_{\mathrm{L}}$, for free bubbles works well for solid particles in the part of the trajectory upstream of the cylinder axis, i.e. for $x<0$. In this region, the particle motion does not seem to be affected by the presence of the cylinder. For $x>0, C_{\mathrm{L}}$ should be higher if the observed repelling action of the cylinder should be accounted for. In this region, the wake structure of the particle might be affected by the presence of the cylinder.

(iv) Because of the importance of the pressure gradient and added mass forces, the numerical modeling is only accurate if nonlinear interpolation methods in the elements are used and if the mesh elements are sufficiently small

Acknowledgements - The author is grateful to J. Essing for his work with FIDAP'" and for building the test rig together with P. Boot, to E. Hoogendam for dedicatedly performing the experiments, to R. den Boer for his work with MATLAB ${ }^{\mathrm{mm}}$ and FIDAP ${ }^{\mathrm{mm}}$, to I. Demirel for analyzing the slides and to F. Ganzevles for general assistance. 


\section{REFERENCES}

Ahmadi, G. and Goldschmidt, V. W. (1971) Motion of particles in a turbulent fluid-the basset history term. J. of Applied Mech. 6, 561-563.

Auton, T. R. (1987) The lift force on a spherical body in a rotational flow. J. Fluid Mech. 183, 199-218.

Auton, T. R., Hunt, J. C. R. and Prud'homme, M. (1988) The force exerted on a body in inviscid unsteady non-uniform rotational flow. J. Fluid Mech. 197, 241-257.

Barkla, H. M. and Auchterlone, L. J. (1971) The magnus or robins effect on rotating spheres. $J$. Fluid Mech. 47, 437-447.

Cantwell, B. and Coles, D. (1983) An experimental study of entrainment and transport in the turbulent near wake of a circular cylinder. J. Fluid Mech. 136, 321-374.

Chang, E. J. M. (1992) Accelerated motion of rigid spheres in unsteady flows at low to moderate Reynolds numbers. Ph.D. thesis, Brown University.

Clift, R., Grace, J. R. and Weber, M. E. (1978) Bubbles, Drops and Particles. Academic Press, New York.

Engelman, M. (1991) FIDAP 7.0 Manuals. Fluid Dynamics Int., Inc.

Hunt, J. C. R., Perkins, R. J. and Fung, J. C. H. (1994) Problems in modeling disperse two-phase flows. In Mechanics USA 1994, ed. A. S. Kobayashi, pp. 49-60. ASME. Appl. Mech. Rev. 47.

Kim, 1., Elghobashi, S. and Sirignano, W. A. (1993) Three-dimensional flow over two spheres placed side by side. J. Fluid Mech. 246, 465-488.

Kim, I. and Pearlstein, A. J. (1990) Stability of the flow past a sphere. J. Fluid Mech. 211, 73-93.

Knubben, G. (1995) Numerical simulation method to predict droplet trajectories for designing induction systems of IC-engines. Ph.D. thesis, Eindhoven University of Technology.

Kourta, A., Boisson, H. C., Chassaing, P. and Minh, H. H. (1987) Nonlinear interaction and the transition to turbulence in the wake of a circular cylinder. J. Fluid Mech. 181, 141-161.

Leal, L. G. (1980) Particle motions in a viscous liquid. Annual Rev. of Fluid Mech. 12, 435-476.

Liang, L. and Michaelides, E. E. (1992) The magnitude of basset forces in unsteady multiphase flow computations. J. of Fluids Eng. 114, 417-419.

Magnaudet, J., Rivero, M. and Fabre, J. (1995) Accelerated flows past a rigid sphere or a spherical bubble. Part 1. Steady straining flow. J. Fluid Mech. 284, 97-135.

Maxey, M. R. and Riley, J. J. (1983) Equation of motion for a small rigid sphere in a nonuniform flow. Phys. Fluids 26, 883-889.

Mei, R. and Adrian, R. J. (1992) Flow past a sphere with an oscillation in the free-stream velocity and unsteady drag at finite reynolds number. J. Fluid Mech. 237, 323-341.

Mei, R. and Klausner, J. F. (1992) Unsteady force on a spherical bubble at finite reynolds number with small fluctuations in the free-stream velocity. Phys. Fluids A 4, 63-70.

Mei, R., Lawrence, C. J. and Adrian, R. J. (1991) Unsteady drag on a sphere at finite reynolds number with small fluctuations in the free-stream velocity. J. Fluid Mech. 233, 613-631.

Melling, A. and Whitelaw, J. H. (1976) Turbulent flow in a rectangular duct. J. Fluid Mech. 78, 289-315.

Meng, H. and van der Geld, C. W. M. (1994) Bubble trajectories in cross-flows and wake entering mechanisms. In Proc. of Int. Heat and Mass Transfer Conf., ed. G. F. Hewitt, Vol. 6, 214-TP-17, pp. 235-240.

Michaelides, E. E. and Feng, Z.-G. (1995) The equations of motion of a small viscous sphere in an unsteady flow with interface slip. Int. J. Multiphase Flow 21, 315-321.

Miyazaki, K., Bedeaux, D. and Avalos, J. B. (1995) Drag on a sphere in slow shear flow. J. Fluid Mech. 296, 373-390.

Mollinger, A. M. (1995) Particle entrainment. Measurement of the fluctuating lift force. Ph.D. thesis, Delft University of Technology.

Naimi, M. and Gessner, F. B. (1994) A calculation method for developing turbulent flow in rectangular ducts of arbitrary aspect ratio. In Boundary Layer and Free Shear Flows, pp. 63-73. ASME. FED-Vol. 184.

Odar, F. and Hamilton, W. S. (1964) Forces on a sphere accelerating in a viscous fluid. J. Fluid Mech. 18, 302-314. 
Sridhar, G. and Katz, J. (1995) Drag and lift forces on microscopic bubbles entrained by a vortex. Phys. Fluids 7, 389-399.

VDI (1991) VDI Wärmeatlas; Berechnungsblätter für den Wärmeübergang. Verein Deutscher Ingenieure, Düsseldorf. 